\title{
EFEITO DE DIFERENTES SUBSTRATOS NA PRODUÇÃO DE MUDAS DE GRAMAS EM BANDEJAS
}

\author{
ALICE NOEMI ARANDA FRANCO \\ Engenheira Agrônoma
}

Orientador: Prof. Dr. KEIGO MINAMI

Dissertação apresentada à Escola Superior de Agricultura "Luiz de Queiroz", Universidade de São Paulo, para obtenção do título de Mestre em Agronomia, Área de Concentração: Fitotecnia.

PIRACICABA

Estado de São Paulo - Brasil

Julho -2000 


\section{Errata}

Pag. xii, $4^{\mathrm{a}}$ linha substituir Axonopus affinis por Axonopus compressus.

Pag. xiv, subsituir Axonopus affinis por Axonopus compressus, Zoysia japonica por Zoysia japonica, Cynodon dactylon por Cynodon dactylon, Zoysia matrella por Zoysia matrella e Stenotaphrum secundatum por Stenotaphrum secundatum.

Pag 12, item 2.3.4, $4^{\mathrm{a}}$ linha, substituir casca pinheiro por casca de pinus.

Pag. 12, item 2.3.4.1, $2^{\circ}$ parágrafo, $2^{\mathrm{a}}$ linha, substituir casca de pinheiro por casca de pinus.

Pag. 20, item $3.2,1^{\circ}$ parágrafo, colocar no final da linha bandejas de 64 células.

Pag. 22, item $3.4,1^{\circ}$ parágrafo, $5^{\mathrm{a}}$ linha, colocar 7680 plantas por época de cultivo.

Pag. 25, item 4.1.1.1.1, $4^{\mathrm{a}}$ linha, substituir variedade por espécie.

Pag. 36, item 4.1.4.1.2, substituir Tabela 1 por Tabela 9.

Pag. 42, item 4.1.5.2.1, $2^{\circ}$ parágrafo, 5a. linha, colocar $145 \mathrm{ml} / \mathrm{L}$. 
Dados Internacionais de Catalogação na Publicaçāo (CIP) DIVISĀO DE BIBLIOTECA E DOCUMENTAÇĀO - Campus "Luiz de Queiroz"/USP

Franco, Alice Noemí Aranda

Efeito de diferentes substratos na produção de mudas de gramas em bandejas / Alice Noemi Aranda Franco. - - Piracicaba, 2000.

54 p. : il.

Dissertação (mestrado) - - Escola Superior de Agricultura Luiz de Queiroz, 2000.

Bibliografia.

1. Cultivo em bandeja 2. Grama 3. Muda 4. Planta de cobertura 5. Planta ornamental 6. Substrato I. Título

CDD 635.964 
A meus queridos pais, Braulio e Daisy.

porque com amor e paciência,

sobretudo nos momentos mais difíceis,

deram-me forças para realizar este sonho

DEDICO

Aos meus queridos sobrinhos Patricia,

Nathalia, Leticia, Sindy e Oscar

pela alegria de suas existências

OFEREÇO 


\section{AGRADECIMENTOS}

À Deus e a Maria Santíssima,

Glorificai-vos-ei, louvar-vos-ei, ó Deus meu salvador; glorificarei o vosso nome porque fostes meu auxílio e minha proteção (Eclo, 51).

À meu querido pai Dr. Braulio Aranda, porque sempre soube me orientar e transmitir valores com o próprio exemplo de vida. Por ser um grande pesquisador;

À Escola Superior de Agricultura "Luiz de Queiroz" pela oportunidade de aperfeiçoamento;

Ao Professor Dr. Keigo Minami pela orientação e apoio durante o curso;

À Organização dos Estados Americanos (OEA), pela concessão da bolsa de estudos;

Ao Professor Dr. Roberval C. S. Ribeiro pela amizade e por suas valiosas sugestões em meus projetos de estudo;

Ao Professor Dr. Octavio Nakano pelo incentivo e ajuda na realização do curso de pós-graduação;

Ao Eng. Agr. Edivaldo Casarini, pela paciência, incondicional ajuda nas grandes dificuldades que passamos juntos, e nas alegrias de nossos pequenos triunfos do dia a dia.

À minha querida irmã Mabel, por seu estímulo e ajuda constante durante todos estes anos que passei longe de casa.

À Itograss Agrícola Ltda. pela doação das mudas, especialmente na pessoa do Eng. Agr. Roberto Guerra Amaral Gurgel, pela ajuda constante;

À Eucatex Química e Mineral Ltda pelo fornecimento dos substratos, na pessoa da Eng. Agr. Barbara Puchala.

Aos colegas e amigos Valeria Modolo, Paulo Araujo, Márcia de Moraes Echer, Salvador Barros Torres, Silvia de Oliveira, Ricardo Kluge e 
Vandeir Francisco Guimarães pela ajuda durante o experimento e na redação da dissertação;

As secretarias do Departamento de Produção Vegetal da ESALQ/USP, Elena, Bete, Celia, Ivette, e Silvia.

Aos funcionários do Departamento de Produção Vegetal e estagiários da PROHORT da ESALQ, pela valiosa ajuda durante a instalação e avaliação dos experimentos; 


\section{SUMÁRIO}

Página

LISTA DE FIGURAS....................................................... viii

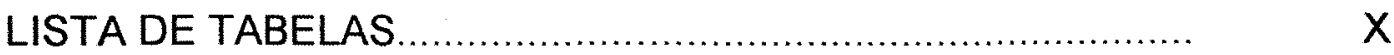

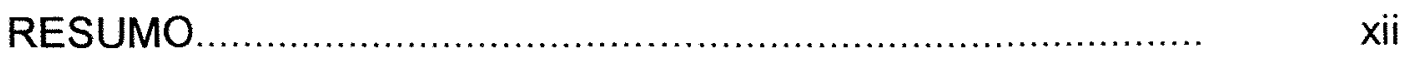

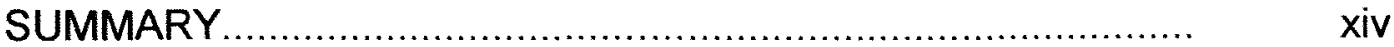

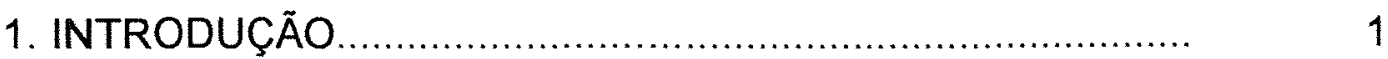

2. REVISÃO DE LITERATURA ...........................................

2.1 Produção de mudas................................................................

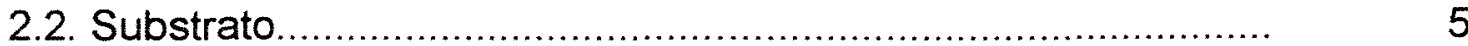

2.3.1 Componentes mais utilizados nas misturas de substratos para produção de mudas......................................................

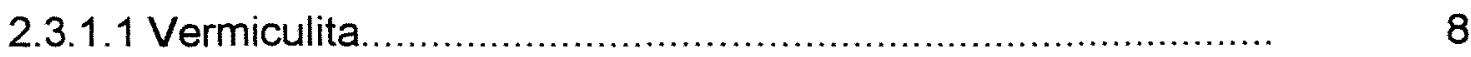

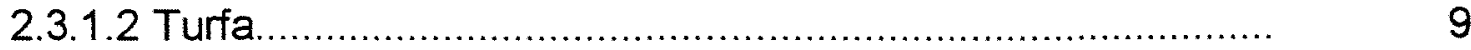

2.3.1.3 Casca de Arroz Carbonizada............................................... 10

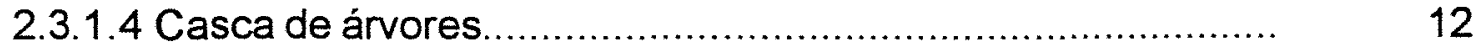

2.3.1.4.1 Casca de Pinus..................................................... 12

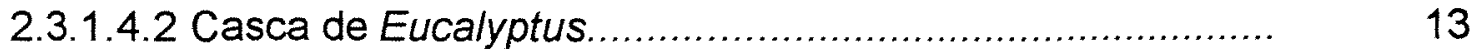

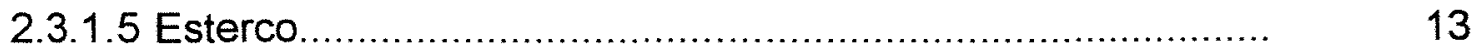

2.4 Espécies de Gramas.............................................................

2.4.1 Grama Zoysia ou Japonesa (Zoysia tenuifolia Trin.)............ 14

2.4.2 Grama Santo Agostinho (Stenotaphrum secundatum (Walt. Watson) Kuntze) ......................................................... 14

2.4.3 Grama Bermuda ou Grama Seda (Cynodon dactylon Rich.). 15

2.4.4 Grama São Carlos ou Grama larga (Axonopus compressus P.Beauv.).............................................................. 15

2.4.5 Grama Esmeralda (Zoysia japonica Steud.)........................ 16

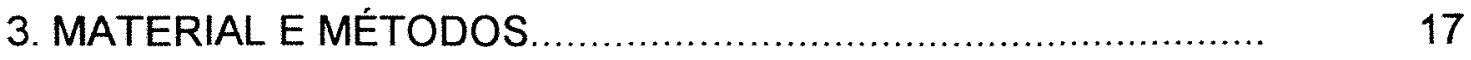

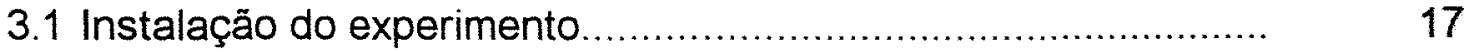


Página

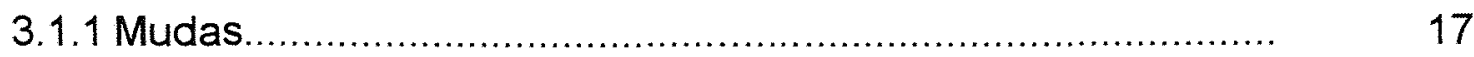

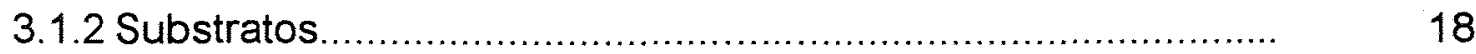

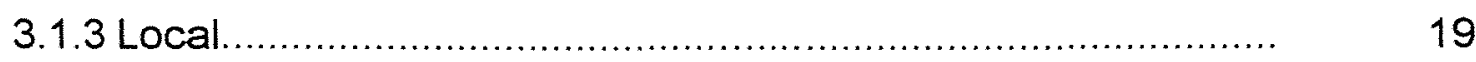

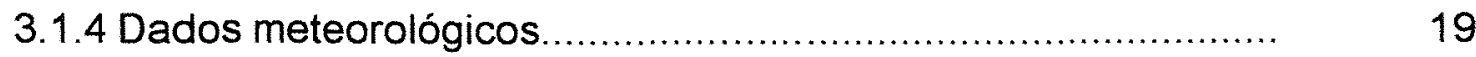

3.2 Condução do experimento................................................... 20

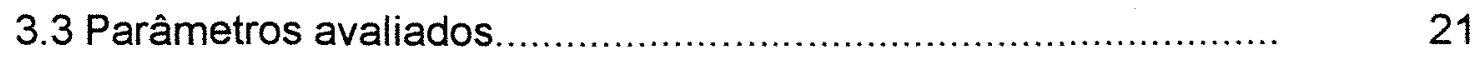

3.3.1 Comprimento médio do sistema radicular (CMSR) .............. 21

3.3.2 Volume da parte aérea (VPA).......................................... 21

3.3.3 Volume do sistema radicular (VR) ................................ 21

3.3.4 Massa seca da parte aérea (MSPA) ................................. 21

3.3.5 Massa seca do sistema radicular (MSR) ......................... 22

3.4 Delineamento experimental e análise estatistica.................... 22

4. RESULTADOS E DISCUSSÃO............................................. 23

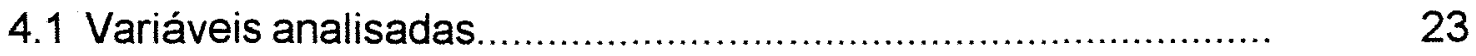

4.1.1Comprimento do sistema radicular (CMSR)......................... 24

4.1.1.1 Primeira e Segunda época............................................ 25

4.1.1.1.1 Espécies de gramas.............................................. 25

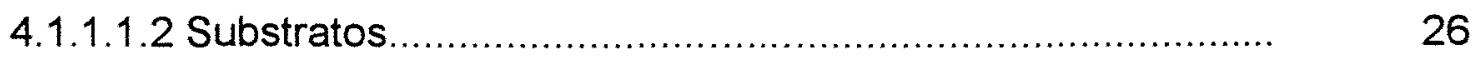

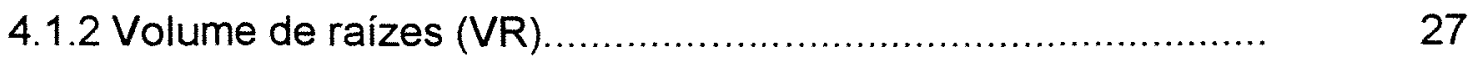

4.1.2.1 Primeira época............................................................. 27

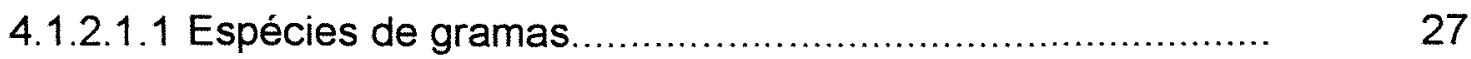

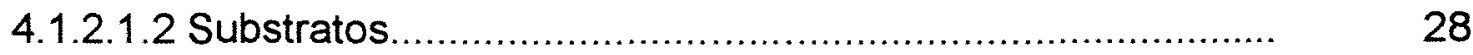

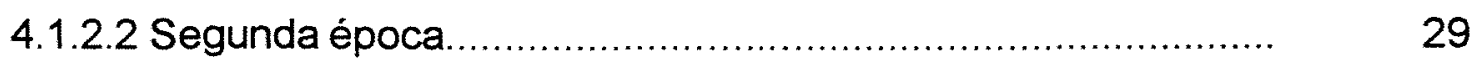

4.1.2.2.1 Espécies de gramas................................................. 29

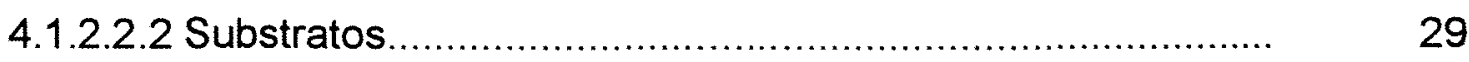

4.1.3 Volume da parte aérea (VPA) ........................................ 30

4.1.3.1 Primeira época....................................................... 30

4.1.3.1.1 Espécies de gramas................................................ 30 
Página

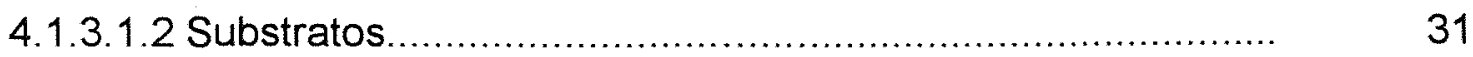

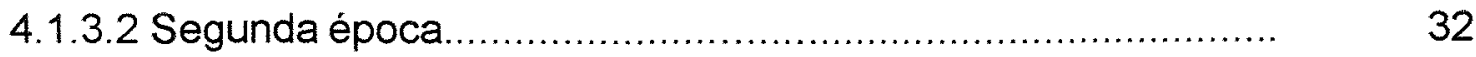

4.1.3.2.1 Espécies de gramas................................................ 32

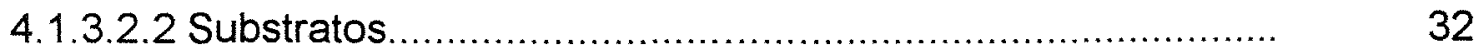

4.1.4 Massa seca do sistema radicular (MSR) ......................... 35

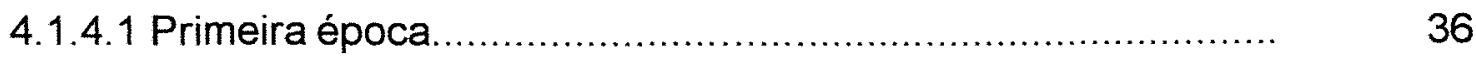

4.1.4.1.1 Espécies de gramas.................................................. 36

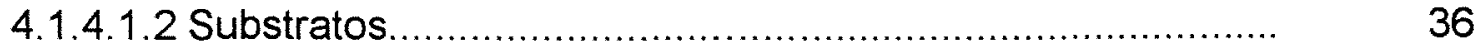

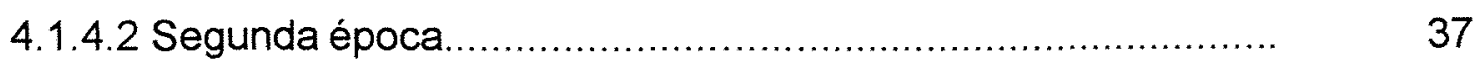

4.1.4.2.1 Espécies de gramas................................................ 37

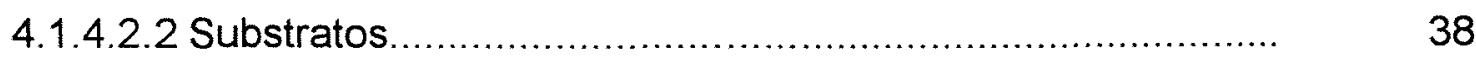

4.1.5 Massa seca da parte aérea (MSPA) ................................... 40

4.1.5.1 Primeira época............................................................. 40

4.1.5.1.1 Espécies de gramas.................................................. 40

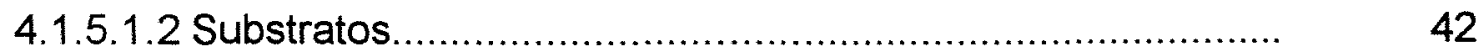

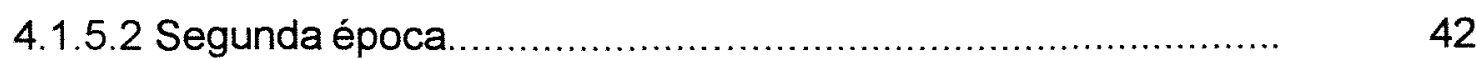

4.1.5.2.1 Espécies de gramas................................................ 42

4.1.5.2.2 Substratos..................................................... 44

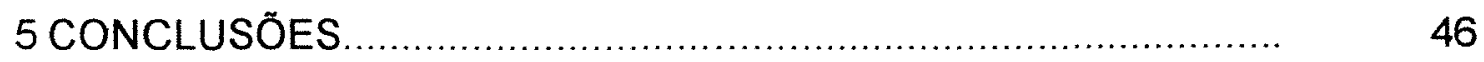

REFERÊNCIAS BIBLIOGRÁFICAS.................................... 48 


\section{LISTA DE FIGURAS}

Página

1 Médias da variável comprimento do sistema radicular (CMSR) para as duas épocas em função das espécies de grama e das misturas de substratos

2 Médias da variável volume de raiz (VR) para as duas épocas em função das espécies de grama e das misturas de substratos

3 Médias da variável volume da parte aérea (VPA) para as duas épocas em função das espécies de grama e das misturas de substratos.

4 Espécies de gramas São Carlos (SC), Santo Agostinho (SA), Bermudas (BE), Esmeralda (ES) e Zoysia ( $Z O)$ testadas nos substratos A, B, C, na segunda época de cultivo (verão)

5 Espécies de gramas São Carlos (SC), Santo Agostinho (SA), Bermudas (BE), Esmeralda (ES) e Zoysia (ZO) testadas nos substratos $D, E, F$, na segunda época de cultivo (verão)

6 Médias da variável matéria seca da raiz (MSR) para as duas épocas em função das espécies de grama e das misturas de substratos 
Página

7 Médias da variável matéria seca da parte aérea (MSPA) para as duas épocas em função das espécie de grama e das misturas de substratos......................................................... 


\section{LISTA DE TABELAS}

Página

1 Nome comum e nome científico das cinco espécies de grama

2 Composição e proporção dos diferentes substratos utilizados durante o trabalho

3 Médias mensais: Insolação média e total, precipitação, umidade relativa do ar, temperatura máxima, minima e média entre maio de 1999 e julho de 1999, medidas pelo posto agrometeorológico do Departamento de Ciências Exatas da ESALQ-USP. (Primeira época: inverno)

4 Médias mensais Insolação média e total, precipitação, umidade relativa do ar, temperatura máxima, mínima e média entre dezembro de 1999 e marco de 2000, medidas pelo posto agrometeorológico do Departamento de Ciências Exatas da ESALQ-USP. (Segunda época: verão)

5 Análise da variância e teste $F$ para as variáveis CMSR, VR, VPA, MSR e MSPA, para as duas épocas, em função dos fatores (causas da variação) espécies de gramas, misturas de substratos, e sua interação. 
6 Médias originais da variável comprimento do sistema radicular (CMSR), para as duas épocas, em função das espécies de grama e substratos

7 Médias originais da variável volume de raiz (VR), para as duas épocas, em função das espécies de grama $e$ substratos

8 Médias originais da variável volume da parte aérea (VPA), para as duas épocas, em função das espécies de grama e substratos.

9 Médias originais da variável massa seca da raiz (MSR), para as duas épocas, em função das espécies de grama e substratos.

10 Médias originais da variável massa seca da raiz (MSPA), para as duas épocas, em função das espécies de grama e substratos 


\title{
EFEITO DE DIFERENTES SUBSTRATOS NA PRODUÇÃO DE MUDAS DE GRAMAS EM BANDEJAS
}

\author{
Autor: Alice Noemi Aranda Franco \\ Orientador: Prof. Dr. Keigo Minami
}

\section{RESUMO}

O presente trabalho teve como objetivo testar substratos contendo diferentes proporções de casca-de-arroz-carbonizada, turfa, casca de pinus, casca de eucaliptus, vermiculita e matéria orgânica na produção de mudas de grama das espécies São Carlos (Axonopus affinis), Esmeralda (Zoysia japonica), Bermudas (Cynodon dactylon), Zoysia (Zoysia matrella) e Santo Agostinho (Stenotaphrum secundatum) em bandejas, sob ambiente protegido em duas épocas de cultivo (verão e inverno). O delineamento experimenta foi blocos casualizados no esquema fatorial, constando cinco espécies de gramas e seis substratos, com quatro repetições para as duas épocas. Os parâmetros avaliados foram: comprimento médio do sistema radicular, volume e matéria seca da parte aérea e raízes. Foram avaliadas aos 60 dias após o plantio 20 mudas por parcela colhidas ao acaso.. Na primeira época, todos os parâmetros avaliados foram não significativos. Para a segunda época, constatou-se que o substrato $A$, composto de casca de arroz carbonizada + vermiculita (1:2), destacou-se em relação aos demais proporcionando os melhores resultados nos parâmetros massa seca de raiz e parte aérea para as espécies Santo Agostinho, Bermudas e Esmeralda. O substrato $B$, composto de (casca de pinus $75 \%+$ casca de eucaliptus $25 \%$ ) + turfa + casca de arroz (1:1:1) carbonizada apresentou as melhores médias na espécie São Carlos (SC). O substratos, C composto de casca de pinus + 
turfa + vermicullita (2:1:1), e D com vermicullita + casca de eucaliptos (2:1) apresentaram os piores resultados com todas as espécies de gramas. O substrato $E$ composto de matéria orgânica + vermicullita (1:2) e $F$ que representa o Plantmax, apresentaram os melhores resultados para as espécies Zoysia e Bermudas. 


\section{EFFECT OF DIFFERENT SUBSTRATES IN THE PRODUCTION OF GRASS SEEDLINGS IN TRAYS}

\section{SUMMARY}

This work had the objective of evaluating alternative substrates with different proportions of carbonized rice hull, peat, pine bark, eucalyptus bark, vermiculite and manure on the production of grass seedlings of species São Carlos ( Axonopus affins), Esmeralda (Zoysia japonica), Bermudas (Cynodon dactylon), Zoysia (Zoysia matrella) and Santo Agostinho (Stenotaphrum secundatum) in trays under greenhouse conditions at two seasons (summer and winter). The experimental scheme was complete randomized blocks with four replications, with five species and six substrates for the two periods. The following parameters were evaluated: average length of root system, volume and dry matter of shoot and roots. After 60 days from planting, 20 seedlings in each set were harvested casually and evaluated. At first season, there were no significance for every parameters evaluated. At second season the substrate $A$, composed of carbonized rice hull + vermiculite (1:2) stood out among the others substrates resulting in better results for dry matter of roots and shoot of species Santo Agostinho, Bermudas and Esmeralda. The substrate B, composed of pine bark $(75 \%)+$ eucalyptus bark $(25 \%)+$ peat + carbonized rice holl (1:1:1) showed better average for São Carlos. The substrates $C$, composed of pine bark + peat + vermiculite $(2: 1: 1)$, and substrate $D$, composed of vermiculite + eucalyptus bark (2:1) showed the worst results in all grass species. Substrate $E$, composed of manure + vermiculite (1:2), and F, composed of Plantmax, showed the best results for the species Zoysia and Bermuda. 


\section{INTRODUÇÃO}

A produção brasileira de flores, assim como de plantas ornamentais utilizadas em jardinagem, ocupa uma área de aproximadamente 4.500 hectares distribuídos nos estados de São Paulo, Rio de Janeiro, Minas Gerais, Santa Catarina e Rio Grande do Sul. Este mercado movimenta em torno de $\mathrm{R} \$ 1$ bilhão ao ano e possui uma taxa de crescimento em torno de $20 \%$ ao ano, podendo ser considerada uma das maiores taxas de crescimento de toda a economia brasileira (Arruda, 1996).

Nos projetos de jardinagem o gramado tem sido adotado como elemento básico, em decorrência da atraente e relaxante cor verde, basicamente constituido por gramíneas. Houve uma época em que gramas de folhas delgadas foram consideradas muito frágeis. Atualmente, suportam tratamento tão rude quanto às espécies mais rústicas, por serem resistentes ao pisoteio, pragas e doenças. A pesquisa de novas espécies possibilitou a introdução de gramas melhoradas, como a Zoysia muito utilizada em jardins orientais; a Santo Agostinho e São Carlos procuradas para jardins residenciais; a Bermuda e Esmeralda, famosas nos campos de esportes, principalmente nos de futebol.

No entanto, o custo de produção tem sido considerado alto, implicando no encarecimento do transporte dos rolos. Além disso, se o lavrador fosse utilizar o solo, tanto a camada fértil quanto o subsolo da própria área de produção, com o decorrer do tempo se produziriam crateras dentro da propriedade o que inviabilizaria a atividade agropecuária, causando um serio impacto ambiental. A recuperação dessas áreas seria extremamente dificil, isso sem contar com que ela estaria perdida como área produtiva (Gonçalves, 1992). 
A produção de mudas em bandejas, tanto as floriferas quanto as folhosas, vem encontrando um mercado crescente. Este sistema permite a utilização de substratos em substituição do solo. Existe hoje uma grande diversidade de subprodutos agrícolas, florestais e minerais gerando resíduos, que poderiam ser utilizados como substratos, puros ou em misturas a custos relativamente menores. Alem disso, também proporciona grandes vantagens, como existe um espaçamento e população predeterminada de plântulas, proporciona mudas de tamanho uniforme; os problemas fitossanitários são mais facilmente controlados. No caso de gramas especificamente, existindo uma menor competição inicial, em muitas espécies, permite a produção de mudas precoces, o que leva a um rápido transplante e a um melhor fechamento no campo.

A produção de mudas de alta qualidade torna-se uma estratégia para melhorar a agricultura em geral, aumentar a competitividade e a exportação, e em certa forma diminuir o impacto ambiental causado no solo. O sucesso numa cultura está em começá-la com mudas boas, que as tornará altamente rentáveis no campo.

Diante do exposto, o presente trabalho teve como objetivo testar substratos alternativos contendo diferentes proporções de casca-de-arrozcarbonizada, turfa, casca de pinus, casca de eucaliptus, vermiculita e matéria orgânica na produção de mudas de grama das espécies São Carlos (Axonopus affinis), Esmeralda (Zoysia japonica), Bermudas (Cynodon dactylon), Zoysia (Zoysia matrella) e Santo Agostinho (Stenotaphrum secundatum) em bandejas, sob ambiente protegido em duas épocas de cultivo (verão e inverno). 


\section{REVISÃO DE LITERATURA}

\subsection{Produção de mudas}

Os problemas dos cultivos implantados no solo se caracterizam pela incidência de pragas e fitopatógenos que atacam o sistema radicular, como os nematóides e as podridões de raizes causadas por fungos e bactérias. Esses problemas de ordem sanitária tendem a se agravar com o decorrer do tempo em conseqüência da alta densidade de cultivo e das dificuldades em realizar o manejo correto do teor de água no solo. Também, podem ocorrer problemas nutricionais freqüentes, pois elementos minerais são absorvidos pelas raizes das plantas e tendem a se acumular na camada superficial do solo, provocando a salinização ou antagonismo entre os nutrientes, com reflexos negativos sobre o rendimento (Andriolo, 1996).

Diante do exposto, a grande vantagem do sistema de mudas é o estabelecimento da cultura com espaçamento ou população pré-determinada de plantas, com mudas de tamanho selecionado e uniforme, diminuição dos problemas fitossanitários, e menor competição inicial (Minami, 1995). Esta fase é de extrema importância, pois dela depende todo o desenvolvimento da cultura. Uma muda mal formada, debilitada, compromete todo o desenvolvimento da cultura, aumentando seu ciclo e ocasionando perda da produção (Souza, 1995).

$\mathrm{Na}$ escolha de um método de produção de mudas deve-se considerar uma série de fatores como a espécie, métodos de propagação, as várias fases do preparo da muda, disponibilidade de solo, mão-de-obra e custos. Qualquer 
sistema utilizado deve produzir mudas que sejam produtivas no campo (Barret, 1981).

A propagação por sementes é um dos métodos principais de reprodução sexual das plantas na natureza e um dos mais eficientes na propagação de plantas cultivadas. A propagação assexual utiliza partes vegetativas da planta original, que colocadas para enraizar estacas, estolhos, etc., cada célula da planta contem a informação genética necessária para gerar uma planta inteira (Hartmann \& Kester 1994 e Minami, 1995).

Para obter bons resultados durante a germinação de sementes e enraizamento de estacas na produção de mudas, são precisas as seguintes características no meio: deve ser suficientemente denso para manter as estacas ou sementes no lugar durante o enraizamento ou germinação; o volume deve ser constante; deve reter suficiente umidade para evitar irrigá-lo com muita freqüência, porém, suficientemente poroso para deixar escorrer a água excessiva e permitir uma aeração adequada (Hartmann \& Kester 1994). Segundo Takeyoshi (1983) um dos fatores mais importantes para o enraizamento de estacas ou estolhos é o substrato, bem como o controle da temperatura, umidade, irrigação e controle de doenças.

Segundo Dutra (1996), dentre os fatores que afetam o enraizamento de estacas e estolhos, o substrato é um dos mais importantes, visto que este pode interferir de maneira diferenciada na formação de raízes, dependendo de suas características físicas e das condições às quais é submetido. Hartmann \& Kester (1994) mencionam que a preferência por este método de propagação reside na facilidade e na rapidez de sua execução, mas pode estar influenciado pelos componentes bioquímicos da própria planta, bem como pelas condições ambientais que envolvem e afetam o processo rizogênico, dentre elas a temperatura.

Jesus (1987) indica que o tamanho do recipiente e o tipo de substrato são aspectos que devem ser investigados para garantia da produção de mudas de boa qualidade. $O$ tamanho do recipiente deve permitir o desenvolvimento do 
sistema radicular sem restrições significativas durante $\circ$ período de permanência no viveiro. Da mesma forma, o substrato excerce uma influência marcante na arquitetura do sistema radicular e no estado nutricional das plantas, afetando profundamente a qualidade das mudas. Keever (1987) relata que o crescimento das raízes, em recipientes ou canteiros, difere do crescimento no campo devido ao volume limitado do substrato pelas paredes do recipiente.

Segundo Silva (1991) na área de hortaliças difundiu-se o uso das bandejas piramidais com as dimensões de $34 \mathrm{~cm}$ de largura, $68 \mathrm{~cm}$ de comprimento e $6 \mathrm{~cm}$ de altura, perfazendo 128 células. O substrato utilizado é um composto de vermiculita mais material orgânico de origem vegetal e adubo. Tal material apresenta ainda como características ausência de patógenos e sementes de plantas daninhas. Sua leveza garante a boa formação do sistema radicular, facilidade no arrancamento das mudas, transporte e plantio.

Segundo Souza (1995), para um melhor aproveitamento da área é necessário a introdução de estufas que possibilitem maior segurança e controle contra intempéries e distúrbios climáticos. A adoção de estufas de arcos semicirculares vêm sendo das mais difundidas. Sua dimensão varia com a quantidade de mudas que se deseja produzir requerendo um planejamento da produção.

\subsection{Substrato}

O termo substrato aplica-se em Horticultura a todo material sólido, distinto do solo, natural, residual, mineral ou orgânico que colocado num recipiente, em forma pura ou em mistura, permite a fixação do sistema radicular, desempenhando, portanto, papel de suporte para a planta (Cadahia, 1998).

A utilização de substratos na produção de mudas de plantas ornamentais tem sido de grande importância. Geralmente são utilizados recipientes que 
demandam grande volume de misturas de solo e matéria orgânica; assim a substituição destes materiais por um substrato ideal contribui de forma substancial para a melhoria da quantidade e qualidade de produção (Stringheta, 1995)

No cultivo em estufas é necessário o uso de substrato para a formação de mudas em recipientes plásticos ou bandejas de isopor, ganhando-se tempo e trabalho. Esse sistema também é mais prático e econômico, comparado com os tradicionais, em canteiros (CATI, 1997). Normalmente para o cultivo em bandejas, há necessidade de substratos uniformes e de boa qualidade quanto as propriedades físicas, químicas e biológicas (Bunt, 1973).

O substrato representa apenas $3 \%$ do custo total de uma produção ornamental, entretanto, melhorias na qualidade de substrato aumentam significativamente a produção, resultando em acréscimos de 10 a $30 \%$ no valor de comercialização (Bakes, 1989).

Segundo Souza (1997), substrato é um componente fundamental. Qualquer variação na sua composição pode significar perda total das mudas. Exerce influência significativa na arquitetura do sistema radicular, no estado nutricional das plantas (Spurr \& Barnes, 1973) e no movimento da água no sistema solo-planta-atmosfera (Orlander \& Due, 1986). Deve ser estéril, com boa capacidade de retenção de água, e isento de impurezas químicas (Minami, 1995).

De acordo com Graziano et al.(1995), não são recomendáveis substratos excessivamente ricos em nutrientes, uma vez que os sais solúveis podem prejudicar o crescimento das plantas. A escolha segundo Gomes (1985), se dá geralmente em função de sua disponibilidade e de suas propriedades físicas, já que muitas vezes são utilizados substratos com baixos teores de nutrientes. Além disso, para Hoffmann (1994) a facilidade de obtenção e baixo custo de aquisição são características importantes que também devem ser consideradas.

Das características físicas, as propriedades de aeração e retenção de umidade são as mais importantes, pois deve haver suficiente espaço poroso 
para permitir a difusão de oxigênio para as raizes (Souza, 1995). A aeração é representada pelo percentual de poros ocupados por ar após a drenagem da água gravitacional, esta é uma característica bastante influenciada pela composição do substrato (Bunt, 1961 e Hodgson, 1981). O valor da porosidade livre ideal para espécies terrestres foi recomendado por Ballester-OImos (1992), que seria de 10 a $20 \%$ na confecção dos substratos. Por outro lado, as partículas argilosas não devem ultrapassar $17 \%$ para evitar encharcamento na mistura (Richard et al., 1964).

Por alterar o desenvolvimento da parte aérea e do sistema radicular diferentemente, a relação raiz parte aérea é afetada por alteraçōes do volume do substrato. Sendo assim, quanto menor volume maior a condição de estresse e conseqüentemente proporciona uma tendência a maior produção de raizes. Isto implica em maiores valores na relação raiz/parte aérea, para os maiores"volumes (Kleepper, 1991).

Entre as características químicas, deve ser, rico em nutrientes, ter composição uniforme, elevada capacidade de troca catiônica (CTC), boa coesão entre partículas ou aderência junto às raizes e ser preferencialmente um meio estéril (Melo, 1989). A condutividade elétrica (EC) é um parâmetro para medir salinidade, que refere-se a concentração de sais solúveis presentes na solução do substrato. A interpretação dos níveis de salinidade - determinada no extrato de saturação do substrato - no cultivo de plantas ornamentais em recipientes foi descrita por Cadahia (1998) da seguinte forma em dS/m: <0,74 muito baixa, 0,75 - 1,99 adequada para a maioria das plantas, embora seja muito baixa se o substrato for pobre em matéria orgânica; 2,00 - 3,49 satisfatória para a maioria das plantas, mas nas espécies sensiveis poderia causar redução no crescimento; acima destes valores é considerada elevada.

As misturas proporcionam maior porcentagem de enraizamento em relação aos componentes puros, no entanto, a importância do substrato aumenta a medida que aumenta a dificuldade de enraizamento (Richer-Leclerc, 
1984). Fachinello (1994) sugere que a viabilidade da utilização de um substrato está em função de seu efeito sobre o enraizamento de cada espécie.

Em razão da diversidade dos substratos, da dificuldade em obter alguns dos condicionadores do solo, assim como sua proporção volumétrica, densidade, aeração, retenção de umidade, $\mathrm{pH}$ e dosagem de fertilizantes, torna-se difícil escolher a mistura que atenda as condições para o ótimo desenvolvimento das plantas (Gomes 1985)

Entre os materiais em uso mais consagrados encontram-se a turfa (considerada como material padrão), compostos orgânicos, resíduos da agroindústria (cascas de árvores, cascas de amendoim, bagaço de cana, entre outros) e solo mineral. É prática regional o uso de materiais como serrapilheira, fibra (ou pó) de xaxim, o que pelas implicações ecológicas são desaconselháveis (Kampf, 1993).

\subsection{Componentes mais utilizados nas misturas de substratos para produção de mudas.}

\subsubsection{Vermiculita}

A vermiculita trata-se de um material produzido artificialmente mediante a expansão da mica sob uma temperatura de $700-800^{\circ} \mathrm{C}$ (Moinereau, 1987 citado por Andriolo, 1999).

Caracteriza-se como um material leve, limpo, sem contaminação de microrganismos (principalmente aqueles provocadores de "damping-off), reciclável, com capacidade de suprir $\mathrm{Mg}$ e $\mathrm{K}$, com alta capacidade de aereação e de retenção de umidade (Minami, 1982.)

É um mineral com alta capacidade de troca catiónica, podendo variar de 100 a $150 \mathrm{meq} / 100 \mathrm{~g}$ (Souza, 1983). Segundo Silva (1991), tem capacidade de absorver 4 a 5 vezes seu próprio peso em água e outros líquidos. Em outros países como Estados Unidos, a vermiculita é muito usada na propagação de 
plantas, utilizando recipientes, conduzidos em ambientes controlados e podendo ser misturada a areia, esterco, solo, xaxim, esfagno dentre outros (Minami, 1982). No Brasil já é muito usada em Horticultura e Floricultura. Trabalhos experimentais indicam resultados positivos para diversas culturas testadas.

Souza (1982) utilizou vermiculita na produção de mudas de eucalipto, obtendo resultados favoráveis na fase de transplante das mudas. Na formação de mudas de violeta africana, Tombolato (1987) obteve maior número de brotações utilizando vermiculita fina $(\varnothing 2,8-8,0 \mathrm{~mm})$ e vermiculita grossa $(\varnothing 8,0$ $20,0 \mathrm{~mm}$ ). Aguiar (1989) constatou que a vermiculita na produção de mudas de eucalipto promoveu bom desenvolvimento da parte aérea e excelente agregação. Gonçalves (1992), nos tratamentos que utilizou maior proporção de vermiculita no enraizamento de mudas de calanchoe, conseguiu um excelente desenvolvimento de raízes, tanto em comprimento como volume. Parece ocorrer uma certa compensação entre a menor disponibilidade de nutrientes e as excelentes propriedades físicas da vermiculita para enraizamento de estacas (Minami, 1980). Mourão Filho (1998) obteve o maior volume de raízes em mudas de laranjeira na combinação de terra, vermiculita e esterco bovino curtido.

\subsubsection{Turfa}

É um material de origem organo-mineral, encontrada em regiōes de baixada, em locais alagadiços. No Brasil existem três tipos, a turfa micro-flora ou hídrica que é bastante fina. Esta é encontrada em lagoas ligadas a rios e lagos de áreas de restinga. A turfa fibrosa ocorre na superficie do solo, proveniente de deposições de substâncias orgânicas pela natureza ou pelo próprio homem. A turfa lenhosa, é formada por resíduos de vegetais lenhosos de grande porte, e é encontrada na superficie do solo (Minami, 1995). 
Segundo Backes (1989), turfa é um solo orgânico presente em grandes depósitos naturais nas regiões de várzeas. A turfa apresenta vantagens como condicionador, pois melhora as caracteristicas físicas, principalmente na redução da densidade de materiais pesados e no aumento da capacidade de retenção de água (Grolli, 1991). Porém, a turfa constitui um recurso natural não renovável, o que compromete seu fornecimento permanente (Grolli, 1991).

Para Gallangher (1975), a turfa é altamente ácida, variando o pH de 3,7 a 4,2 , portanto, impróprio para a maioria das plantas. Algumas plantas poderiam crescer com adição de fertilizantes, mas a grande maioria precisariam de calagem. Algumas características químicas e físicas da turfa, segundo Kampf (1992), são a alta porcentagem de matéria orgânica, alta capacidade de troca catiônica, baixa densidade, alta capacidade de retenção e água, média capacidade de aeração, alto poder tampão e baixo nivel de nutrientes.

No Brasil, Jung et. al (1987) realizaram estudos, visando a determinação da necessidade de calagem em turfas do Município de Viamão, no Rio Grande do Sul, para sua utilização como substrato para plantas. Estes autores obtiveram uma correlação positiva, relacionando os valores de pH estabilizado, com o aumento das doses de carbonato de cálcio utilizadas, permitindo estimar a quantidade de $\mathrm{CaCO}_{3}$, necessária à turfa, para que o $\mathrm{pH}$ da mesma possa ser elevado a um nível desejado.

\subsubsection{Casca de Arroz Carbonizada}

Tanaka (1973) citado por Souza (1993), considera a casca de arroz como o material ideal para o desenvolvimento de plantas, pelo fornecimento de nutrientes, pela ativação microbiana no solo e pela melhoria da natureza física e química do meio de crescimento e desenvolvimento das culturas.

Segundo Minami (1995) e Kampf (2000), é um material de baixa densidade, baixa capacidade de retenção de água, porém superior à da areia. Oferece boa aeração, drenagem rápida e eficiente e apresenta valor de $\mathrm{pH} \mathrm{em}$ 
torno da neutralidade e rico em minerais, principalmente cálcio e potássio. Possui características semelhantes à fibra de xaxim, podendo tornar-se um substituto deste, pois suas reservas naturais são limitadas (Backes, 1989).

Souza (1995), estudando a proporção dos componentes para substrato, relatou o efeito das misturas no aumento da retenção de água, bem como na quantidade e qualidade da produção de crisântemo em vaso. Indica que a mistura de solo, areia, casca de arroz carbonizada, na proporção volumétrica 2:1:4 propiciou melhor crescimento e floração do crisântemo.

Souza (1993) menciona que a casca de arroz carbonizada é um componente do substrato usado com sucesso na propagação vegetativa da pimenta-do-reino, podendo ser usada para formação de mudas de diversas espécies de plantas, seja pura ou misturada com outros materiais.

Kampf (1993), estudando substratos para produção de mudas de tomate e amor-perfeito, obteve resultados favoráveis nas diferentes misturas realizadas com casca de arroz. O sistema radicular desenvolveu-se com mais vigor, proporcionando plantas com maior peso, altura e número de folhas. As melhores mudas de tomate e amor-perfeito foram obtidas tanto nas combinações de turfa 50 e $33 \%$ de casca de arroz carbonizada. Nakamura e Wabe (1974) estudaram o efeito da adição de casca de arroz ao solo para o cultivo de diferentes plantas. Observaram que esta adição conferiu abundante aeração do substrato, além de aumentar a retenção de água.

Segundo Kasmov (1974), a adição da casca de arroz carbonizada na proporção de $1: 1$, melhora as propriedades físicas do substrato, com um aumento de até $19 \%$ na produção de pimentão e que a mistura de solo mais casca de arroz carbonizada proporcionou um acréscimo $8 \%$ na produção de tomates quando comparada a mistura solo-composto orgânico. 


\subsubsection{Casca de árvores}

Casca de árvores são utilizadas há anos em Horticultura. Os gêneros utilizados na sua maioria são Pinus, Picca, Abies, Sequoia, Pseudotsuga, Fagus, Betula e Quercus, e a espécie Cupressus macrocarpa (Ballester-Olmos, 1992). De acordo com o mesmo autor, no Brasil a casca de pinheiro como subproduto da exploração silvicultural, é considerado um componente de grande interesse no cultivo de plantas epifitas na proporção de $80 \%$, podendo ser combinado com turfa ou poliestireno expandido.

\subsubsection{Casca de Pinus}

As cascas de pinus são classificadas como madeiras de fácil decomposição (Macdonald, 1993). É um material curado e moído, apresentando-se na forma de fragmentos de tamanhos variáveis, composto de celulose e outros carboidratos similares (Gonçalves, 1992).

Na França, Lemaire et al. (1988) estudaram produtos à base de fibras de duas espécies de pinheiro, Pinus pinaster Alt e Pinus silvestris L., submetidas a tratamentos de vapor e observaram seu bom desempenho para cultivo de plantas ornamentais em vasos. Kanashiro (1999), concluiu que os substratos formulados com casca de Pinus, turfa e perlita nas proporções 5:4:1 e 8:1:1, foram as misturas que apresentaram os melhores resultados na produção de bromélias em vasos. Já para Gonçalves (1992), estudando substratos para enraizamento de estacas de calanchoe, observou que os piores desempenhos foram nas misturas de casca de pinheiro e vermiculita. Para Verdonck (1980), a casca de pinheiro seco utilizado como substrato em plantas ornamentais sensiveis como Cordiline terminalis foram afetadas no terceiro período de crescimento. 


\subsubsection{Casca de Eucalyptus}

Dematte (1996) fez um estudo comparativo de substratos vegetais para orquídeas epifitas tendo o xaxim como referencial. No que tange a adsorção e perda de água, e em termos de comportamento com relação a água, os substratos mais recomendáveis para substituir o xaxim foram a casca de Eucalyptus em mistura com casca de coco. Também observou que a casca de Eucalyptus grandis Hill ex Maiden no cultivo de orquídeas epifitas durante três anos, observou que $\circ \mathrm{pH}$ variou de 4,0 a 4.7 após três anos de cultivo. A utilização isolada da casca de Eucalyptus grandis não mostrou-se viável pelas alterações estruturais que prejudicaram a porosidade no cultivo de orquídeas epífitas.

A Ripasa Florestal S.A., na produção de mudas florestais, utiliza como substrato um composto orgânico á base de casca de eucalipto semidecomposta. Este componente corresponde a $90 \%$ do volume de substrato, ao qual são adicionados $10 \%$ de cinza de caldeira, utilizada como fonte de potássio, calcio e micronutrientes (Gonçalves, 1987). Segundo Sheps \& Souza (1988), a casca de eucalipto compostada substitui a vermiculita mineral, tradicionalmente usada pelos produtores de mudas de eucalipto com notável economia de custo.

\subsubsection{Esterco}

Mourão Filho (1998), pesquisando o efeito da composição do substrato nas mudas de laranjeira, observou que plantas de limoeiro Cravo e citruneleiro Swingle produziram valores altos de massa verde com substratos que apresentavam esterco bovino na sua composição. Mattos et. al (1988) constataram efeito significativamente superior dos substratos a base de esterco de galinha no desenvolvimento de mudas de citros. 
A matéria orgânica é composta de diversos componentes que diferem na taxa de decomposição ou no efeito de fertilização, especialmente na transformação do nitrogênio (Kanamori e Yasuda, 1977).

\subsection{Espécies de Gramas}

Existem mais de oito mil espécies de gramíneas, algumas muito diferentes das populares gramas quanto ao aspecto e ao porte. Na formação de um gramado as mais procuradas são a Zoysia, Santo Agostinho, Bermuda, São Carlos e Batatais.

\subsubsection{Grama Zoysia ou Japonesa (Zoysia tenuifolia Trin.)}

É uma herbácea rizomatosa, perene, rasteira das llhas Mararenas (Lorenzi, 1995). Apresenta folhas estreitas, macias, curtas (máximo de 5 a $6 \mathrm{~cm}$ de altura) e de cor verde. As raízes são abundantes e os estolões penetrantes. Esta espécie resiste ao pisoteio, pragas e plantas daninhas. Levemente exigente a luz; o pH ideal está na faixa de 5,5 e 7,0 (Richter, 1983) Adapta-se bem nas regiões litorâneas, pois suporta com facilidade 0 ar salino. Porém, como outras gramas de clima quente, suas folhas escurecem quando ocorre geada e não voltam a ficar verdes enquanto a temperatura permanecer abaixo $10^{\circ} \mathrm{C}$. O seu plantio vai de outubro a novembro (Plantas \& Flores, 1971) Muito usada em jardins e áreas recreativas (Richter, 1993).

\subsubsection{Grama Santo Agostinho (Stenotaphrum secundatum (Walt. Watson) Kuntze) \\ É uma herbácea perene, rizomatosa da América Sub-Tropical (Lorenzi,} 1995). As folhas são largas e verdes com listas; os estolões são longos. Esta espécie produz grande número de sementes. Resiste a pragas e plantas 
daninhas. Exige $\mathrm{pH}$ na faixa de 6,0 a 7,0. Alastra-se bem e cresce ao sol ou na sombra que seja adubada e irrigada constantemente (Richter, 1983).

É notavelmente ornamental pela folhagem verde um tanto delicada e pelo crescimento moderado. Não resiste ao pisoteio, mas é bastante tolerante a salinidade das regiões litorâneas, onde é nativa (Lorenzi, 1995)

Muito utilizada em jardins, é ótima para contrastes e decorações (Richter, 1983).

\subsubsection{Grama Bermuda ou Grama Seda (Cynodon dactylon Rich.)}

Suas folhas são estreitas, macias e de cor verde-escuro; os estolões são longos. Desenvolve-se rapidamente, resiste ao pisoteio e a estiagem; susceptível as pragas; essa espécie exige solo fértil e regas; é de corte fácil, por ter hábitos rasteiros (Richter, 1985)

A grama-seda comum propaga-se por mudas ou sementes, plantadas na primavera ou no verão. A maioria das variedades exige sol pleno, mas alguns híbridos toleram sombra leve. Todos os híbridos devem ser cultivados a partir de mudas (Plantas \& Flores, 1971)

Muito procuradas para jardins, campos de futebol, golfe, pátios de recreação infantil (Itograss, 1997).

\subsubsection{Grama São Carlos ou Grama larga (Axonopus compressus P.Beauv.)}

É uma herbácea rizomatosa, rasteira, nativa do sul do Brasil (Lorenzi, 1999). As suas folhas são largas, compridas, ásperas e de tonalidade verdeclaro; as hastes são rasteiras, se propaga por mudas (Richter, 1983).

Nativa de lugares úmidos, é tolerante ao frio. Cresce no sol e na meiasombra. Necessita de irrigações periódicas por não ser resistente a seca (Lorenzi, 1999). Prefere solos arenosos bem drenados; o pH ideal esta na faixa 
de 4,7 e 7,0. (Richter, 1983). O crescimento é pouco intenso, embora forma um gramado bastante denso (Itograss, 1997)

Muito comum em parques, jardins e áreas de recreação (Richter, 1983).

\subsubsection{Grama Esmeralda (Zoysia japonica Steud.)}

É uma herbácea rizomatosa, reptante, perene muito ramificada, proveniente do Japão (Lorenzi, 1995). As folhas são estreitas e médias, enraizamento abundante; cor verde esmeralda; estolões penetrantes. Forma um perfeito tapete de grama com os estolões e folhas bem entrelaçadas; grande beleza; folhas macias. Precisa de adubação para manter a coloração intensa. (Itograss, 1997).

Esta espécie viceja em solo com pH entre 5,5 e 7, mas recebendo umidade e edubação adequadas pode desenvolver-se em solos mais ácidos (até 4,5) ou mais alcalinos (até 7,5) (Plantas \& Flores, 1971).

Apropriada para a formação de gramados domésticos a pleno sol em substituição da grama-batatais e a grama santo-agostinho, por ter folhagem mais delicada e por exigir podas menos freqüentes. É mais rustica do que as demais espécies de zoysia, entretanto não resiste tanto ao pisoteio quanto a grama-batatais e é menos tolerante ao sombreamento que a grama são-carlos (Lorenzi, 1995).

Muito usada em jardins residenciais, áreas industriais, casas de campo e praia, "playground" e campos de esportes em geral (Itograss, 1997). 


\section{MATERIAL E MÉTODOS}

O experimento foi instalado no Departamento de Produção Vegetal da Escola Superior de Agricultura "Luiz de Queiroz", Universidade de São Paulo, no município de Piracicaba-SP, que apresenta as seguintes coordenadas geográficas $22^{\circ} 43^{\prime}$ de latitude Sul, $47^{\circ} 38^{\prime}$ de longitude Oeste e $540 \mathrm{~m}$ de altitude

O trabalho foi realizado em duas épocas: nos meses de inverno (maio julho 1999) e nos meses de verão (dezembro 1999 - fevereiro 2000) em ambiente protegido.

\subsection{Instalação do Experimento}

\subsubsection{Mudas}

A primeira etapa do experimento (inverno) foi iniciada em 20 de maio de 1999 até 20 de julho de 1999, e a segunda etapa (verão) 16 dezembro de 1999 até 20 de fevereiro de 2000. As mudas das cinco espécies foram fornecidas pela Empresa Itograss Agrícola Ltda., especializada na produção de grama, sediada em Itapetininga, SP. Foram transportadas para instalação do experimento em sistemas de rolos.

O nome comum e científico utilizados durante o trabalho, está descrito na tabela 1. 
Tabela 1. Nome comum e nome científico das cinco espécies de grama.

\begin{tabular}{ll}
\hline Nome Cientifico & Nome Comum \\
\hline Axonopus compressus P.Beauv. & São Carlos \\
Cynodon dactylon Rich. & Bermudas \\
Stenotaphrum secundatum (Walt. Watson) Kuntze & Santo Agostinho \\
Zoysia japonica Steud. & Esmeralda \\
Zoysia tenuifolia Trin. & Zoysia \\
\hline
\end{tabular}

\subsubsection{Substratos}

As mudas foram cultivadas nas diferentes misturas de matérias primas como: vermiculita, o composto pronto casca de Pinus, $75 \%$ + casca de Eucalyptus $25 \%$, turfa, casca de Pinus, casca de Eucalyptus, e o substrato comercial Plantmax fornecidas pela empresa Eucatex, Química e Mineral Ltda com sede em São Paulo. A casca de arroz e do esterco bovino foram provenientes do Departamento de Produção Vegetal da ESALQ/USP.

Os substratos foram formulados utilizando-se matérias primas em diferentes proporções conforme a tabela 02 .

Tabela 2. Composição e proporção dos diferentes substratos com as respectivas siglas utilizadas durante o trabalho.

\begin{tabular}{lcc}
\hline \multicolumn{1}{c}{ Substratos } & Proporções & Siglas \\
\hline casca de arroz carbonizada + vermiculita & $1: 2$ & $\mathrm{~A}$ \\
$\begin{array}{l}\text { (casca de pinus } 75 \%+\text { casca de eucaliptus } 25 \%)+ \\
\text { turfa + casca de arroz carbonizada }\end{array}$ & $1: 1: 1$ & $\mathrm{~B}$ \\
casca de Pinus + turfa + vermicullita & $2: 1: 1$ & $\mathrm{C}$ \\
vermicullita + casca de Eucalyptus & $2: 1$ & $\mathrm{D}$ \\
matéria orgânica + vermicullita & $1: 2$ & $\mathrm{E}$ \\
Plantmax & 1 & $\mathrm{~F}$ \\
\hline
\end{tabular}




\subsubsection{Local}

As dimensões da estufa eram de $5 \mathrm{~m}$ de largura e $15 \mathrm{~m}$ de comprimento como medidas internas, $2 \mathrm{~m}$ de pé direito e a altura do vão central de $4,0 \mathrm{~m}$. Foi classificada como modelo arco com pé direito e a orientação da construção foi no sentido norte-sul de acordo com seu comprimento.

A cobertura da estufa e seu fechamento lateral foram feitos com plástico transparente de 70 micras de espessura.

\subsubsection{Dados meteorológicos}

Os dados de Insolação média e total, precipitação, umidade relativa do ar, temperatura máxima, mínima e média do ar foram medidos pelo posto agrometeorológico do Departamento de Ciências Exatas da ESALQ/USP. Encontra-se localizado a uma altitude de $547 \mathrm{~m}$, e nas coordenadas $22^{\circ} 42^{\prime} 30^{\prime \prime}$ latitude sul e $47^{\circ} 38^{\prime} 30^{\prime \prime}$ longitude oeste de Greenwich.

As médias mensais das duas épocas de cultivo são apresentadas nas tabelas 3 e 4 .

Tabela 3. Médias mensais: Insolação média e total (I), precipitação (P), umidade relativa do ar (UR), temperatura máxima, mínima e média entre maio de 1999 e julho de 1999, medidas pelo posto agrometeorológico do Departamento de Ciências Exatas da ESALQ-USP. (Primeira época: inverno)

\begin{tabular}{|c|c|c|c|c|c|c|c|}
\hline \multirow[t]{2}{*}{ Mês } & \multicolumn{2}{|c|}{$I(h / d)$} & \multirow{2}{*}{$\underset{(\mathrm{mm})}{P}$} & \multirow{2}{*}{$\begin{array}{l}\text { U R } \\
(\%)\end{array}$} & \multicolumn{3}{|c|}{$\mathrm{T}^{\circ} \mathrm{C}$. } \\
\hline & Média & Total & & & Máx & Min. & Méd. \\
\hline Mai/99 & 7,4 & 230,8 & 51,3 & 79,0 & 25,4 & 11,2 & 18,3 \\
\hline Jun/99 & 6,0 & 179,5 & 68,6 & 83,0 & 23,9 & 11,0 & 17,5 \\
\hline Jul/99 & 6,7 & 207,6 & 2,7 & 77,0 & 26,4 & 12,0 & 19,2 \\
\hline
\end{tabular}


Tabela 4. Médias mensais: Insolação média e total (I), precipitação (P), umidade relativa do ar (UR), temperatura máxima, mínima e média entre dezembro de 1999 e marco de 2000 , medidas pelo posto agrometeorológico do Departamento de Ciências Exatas da ESALQ-USP. (Segunda época: verão)

\begin{tabular}{|c|c|c|c|c|c|c|c|}
\hline \multirow[t]{2}{*}{ Mês } & \multicolumn{2}{|c|}{$I(h / d)$} & \multirow{2}{*}{$\begin{array}{c}P \\
(\mathrm{~mm})\end{array}$} & \multirow{2}{*}{$\begin{array}{l}\text { U R } \\
(\%)\end{array}$} & \multicolumn{3}{|c|}{$\mathrm{T}^{\circ} \mathrm{C}$} \\
\hline & Média & Total & & & Máx. & Min. & Méd. \\
\hline Dez/99 & 7,2 & 224,1 & 269,9 & 78,0 & 30,6 & 19,0 & 24,8 \\
\hline Jan $/ 00$ & 6,3 & 197,5 & 235,9 & 82,6 & 30,2 & 19,0 & 24,6 \\
\hline Fev/00 & 5,4 & 159,3 & 124,0 & 86,5 & 29,9 & 19,2 & 24,5 \\
\hline
\end{tabular}

\subsection{Condução do experimento}

Para a produção de mudas utilizou-se o sistema de bandejas de cor preta, de plástico descartável, de $24 \mathrm{~cm}$ de comprimento por $24 \mathrm{~cm}$ de largura e $6 \mathrm{~cm}$ de altura.

Foram utilizadas 120 bandejas por época de cultivo, lavadas e desinfetadas com uma solução de hipoclorito de sodio comercial a 10\%.

No dias 19/05/99 e 15/12/99, primeira e segunda época de cultivo respectivamente, as bandejas foram preenchidas com os diferentes substratos de acordo com cada tratamento e posteriormente plantadas com estolhos de 3 a 5 gemas em cada célula das cinco espécies de grama Bermudas, Esmeralda, São Carlos, Santo Agostinho e Zoysia. Após o plantio foi realizada uma irrigação e posteriormente transportadas à casa de vegetação e apoiadas em suportes de ferro a $0,50 \mathrm{~m}$ do solo.

As bandejas permaneceram em casa de vegetação até os dias 20/07/99 e 20/02/00 respectivamente. Durante estes períodos as irrigações foram feitas por microaspersão através de um sistema automatizado. Nos meses de verão, quando acontece maior evapotranspiração, eram realizadas geralmente 4 
irrigações de 3 minutos por dia, porém a programação do horário e intervalo de irrigação poderiam variar conforme as condições de temperatura e umidade do ambiente. Já nos meses de inverno o intervalo de irrigação foi de 2 vezes por dia com 3,5 minutos de duração.

\subsection{Parâmetros avaliados}

\subsubsection{Comprimento do sistema radicular (CMSR)}

A dimensão considerada foi mensurada no sentido do maior comprimento da base até o extremo da raiz, utilizando-se régua graduada em $\mathrm{cm}$.

\subsubsection{Volume da parte aérea (VPA)}

As folhas destacadas manualmente foram levadas ao laboratório, onde foi determinado o volume da parte aérea para cada planta. Este parâmetro foi obtido por diferença do volume extravasado do recipiente logo após da imersão em água da amostra vegetal. Por leitura direta se obtém o volume dessa amostra. A vidraria utilizada foi proveta e becker graduados (100 ml.).

\subsubsection{Volume do sistema radicular (VR)}

Para a retirada do substrato, o sistema radicular foi imerso em água e posteriormente lavado com lavadora de alta pressão, marca Kärcher, modelo 410 , sendo as raizes contidas por uma peneira de granulação $n^{\circ} 14$ para evitar a perdas das mesmas. Determinou-se o volume seguindo a metodologia descrita no item 3.3.2.

\subsubsection{Massa seca da parte aérea (MSPA)}

Após a determinação do volume as folhas foram acondicionadas em sacos de papel kraft para secagem em estufa, marca Marconi, modelo MA 037, dotadas de sistema para circulação e renovação de ar a uma temperatura de 
$68^{\circ} \mathrm{C}$, até atingir peso constante. Após a secagem, o material foi pesado em balança analítica, marca Marte, modelo AS 200.

\subsubsection{Massa seca do sistema radicular (MSR)}

Logo após a determinação do volume do sistema radicular, determinouse a matéria seca seguindo a metodologia descrita no item 3.3.4

\subsection{Delineamento experimental e análise estatística}

O delineamento experimental aplicado foi em blocos ao ocaso em esquema fatorial $5 \times 6$, constando cinco espécies Bermudas, Esmeralda, São Carlos, Santo Agostinho e Zoysia e seis diferentes substratos (A, B, C, D, E, F). Segundo este modelo, cada bloco foi formado pela combinação de cinco espécies de grama e seis substratos, que com quatro repetições perfazem um total de 120 parcelas, para cada época de cultivo, inverno e verão.

Nas duas épocas de cultivo foi realizada uma coleta para avaliação aos 60 dias após o plantio, onde em cada uma delas foram amostradas 20 plantas colhidas ao acaso desprezando-se a bordadura, obtendo-se um valor médio para cada avaliação.

O esquema de análise da variância e teste $F$ para os tratamentos foi o seguinte:

\begin{tabular}{|c|c|c|c|c|}
\hline $\begin{array}{c}\text { Causas da } \\
\text { Variação }\end{array}$ & G.L & S.Q. & Q.M. & $\bar{F}$ \\
\hline Blocos & 3 & SQ Blocos & & \\
\hline $\begin{array}{l}\text { Espécies de } \\
\text { gramas }\end{array}$ & 4 & SQ Variedade & QM Espécie & QM E /QM Res \\
\hline Substratos & 5 & SQ Substrato & QM Substrato & QM E /QM Res \\
\hline Espécies $x$ & 20 & SQEspéc. $x$ & QM Espécie $x$ & QM ExS./QMRes \\
\hline Substrato & & Subst. & Subst. & \\
\hline Residuo & 87 & SQ Resíduo & QM Resíduo & \\
\hline Total & 119 & SQ Total & & \\
\hline
\end{tabular}




\section{RESULTADOS E DISCUSSÃO}

\subsection{Variáveis analisadas}

A análise da variância para as variáveis: comprimento do sistema radicular (CMSR), volume de raiz (VR), volume da parte aérea (VPA), massa seca da raiz (MSR) e massa seca da parte aérea (MSPA), para as duas épocas (inverno e verão), em função das causas de variação (fatores) em estudo: espécies de gramas e substratos, e sua interação, encontram-se na Tabela 5.

Pela Tabela 5 pode-se observar que foram detectadas, para as variáveis CMSR, VR e VPA, nas duas épocas (inverno e verão), diferenças significativas para os efeitos principais, ou seja, entre as espécies de gramas e entre os substratos. Para as variáveis CMSR e VPA a diferença foi ao nivel de $1 \%$ nas

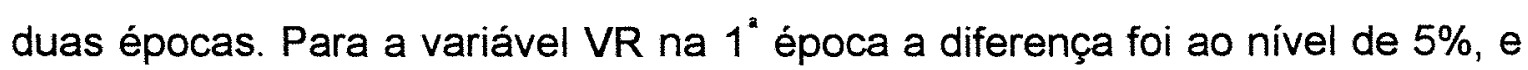
na $2^{a}$ época ao nível de $1 \%$. Com relação a interação dos fatores espécies $\times$ substratos o teste $F$ não acusou diferença significativa para nenhuma dessas variáveis.

Para a variável MSR (Tabela 5), na $1^{2}$ época (inverno) somente o fator espécies de gramas foi significativo ao nivel de $1 \%$, enquanto que para a $2^{2}$ época os fatores espécies de gramas, substratos e a interação deles foram significativos ao nivel de $1 \%$.

Para a variável MSPA (Tabela 5), na $1^{2}$ época (inverno) somente os fatores principais foram significativos ao nivel de $1 \%$, enquanto que para a $2^{2}$ época (verão) todos os fatores principais e a interação entre eles foram significativos ao nivel de $1 \%$. 
Tabela 5 - Análise da variância e teste $F$ para as variáveis CMSR, VR, VPA, MSR e MSPA, para as duas épocas, em função dos fatores (causas da variação) espécies de gramas, substratos, e sua interação.

\begin{tabular}{|c|c|c|c|c|c|c|}
\hline \multicolumn{7}{|c|}{$11^{2}$ ÉPOCA (Inverno) } \\
\hline \multirow[b]{2}{*}{ Causas de Variaç. } & \multirow[b]{2}{*}{ G.L. } & \\
\hline & & \multicolumn{2}{|c|}{$\frac{\text { Quadrados Médios }}{\text { VR* }^{*}}$} & $\mathrm{VPA}^{*}$ & $\mathrm{MSR}^{*}$ & MSPA* $^{*}$ \\
\hline Blocos & 3 & 3,262 & 70,858 & 158,100 & 0,095 & 0,106 \\
\hline Espécies & 4 & $118884^{\star *}$ & $17966^{*}$ & $40806^{\star \star}$ & $0149 * *$ & $0.337^{\star * *}$ \\
\hline Substratos & & $11.947^{\star *}$ & $17799^{*}$ & $56638 * *$ & $0.033^{\text {ns }}$ & $0156^{* * *}$ \\
\hline Espec. $\times$ Subst. & & $1502^{\text {ns }}$ & $1013^{\text {ns }}$ & $8210^{\text {ns }}$ & & \\
\hline Resíduo & 87 & 2,263 & 5,497 & 6,639 & 0,019 & 0,027 \\
\hline Total & 119 & 773,797 & 948,497 & 1662,621 & 3,149 & 5,375 \\
\hline Coef. Variação (\%) & & 13,80 & 10,87 & 11,60 & 21,67 & 21,93 \\
\hline \multicolumn{7}{|c|}{$2^{2}$ ÉPOCA (Verão) } \\
\hline Causas de Variaç. & G.L. & CMSR & VR & VPA & MSR & MSPA \\
\hline Blocos & 3 & 8,549 & 20,140 & 20,498 & 0,970 & 0,612 \\
\hline Espécies & 4 & $50,679^{\star *}$ & $56,377^{\star \star}$ & $85,178^{\star \star}$ & $0,301^{\text {t**}}$ & $0,671^{* *}$ \\
\hline & 5 & $7,261^{* *}$ & $35,588^{\star *}$ & $51,597^{* *}$ & $0,535^{\star \star *}$ & $1,453^{\text {** }}$ \\
\hline Espéc.. $\times$ Subst. & 20 & $1,878^{\text {ns }}$ & $9,427^{\text {ns }}$ & $11,452^{\text {ns }}$ & $0,192^{\star \star}$ & $0,276^{\text {***}}$ \\
\hline Residuo & 87 & 2,101 & 6,582 & 7,526 & 0,077 & 0,088 \\
\hline Total & 119 & 485,021 & 1225,077 & 1543,974 & 17,335 & 24,984 \\
\hline Coef. Variação (\%) & & 15,65 & 24,05 & 25,82 & 36,96 & 29,94 \\
\hline
\end{tabular}

\subsubsection{Comprimento do sistema radicular (CMSR)}

A Tabela 6 mostra as médias originais e teste de Tukey para a variável comprimento do sistema radicular (CMSR), devidas às espécies de gramas e substratos obtidas na $1^{\mathrm{a}}$ época (inverno) e $2^{\mathrm{a}}$ época (verão). 
Tabela 6. Médias originais da variável comprimento do sistema radicular (CMSR), para as duas épocas, em função das espécies de gramas e substratos.

\begin{tabular}{|c|c|c|c|c|c|c|c|}
\hline \multicolumn{8}{|c|}{$1^{2}$ ÉPOCA - Inverno } \\
\hline \multirow[b]{2}{*}{ Espécies } & \multicolumn{6}{|c|}{ Substratos } & \multirow[b]{2}{*}{ Médias } \\
\hline & A & $B$ & $\mathrm{C}$ & D & $E$ & $F$ & \\
\hline Santo Agostinho & 14,26 a A & 14,55 a $A$ & 14,41 a $A$ & 14,35 a $A$ & 14,18 a $A$ & 16,26 a $A$ & 14,67 a \\
\hline São Carlos & 9,47 a $A$ & 10,79 a $A$ & 12,03 a $A$ & 9,75 a $A$ & 10,44 a $A$ & 11,41 a $A$ & $10,65 \mathrm{~b}$ \\
\hline Bermudas & 10,05 a $A$ & 9,91 a $A$ & 9,65 a $A$ & 9,49 a $A$ & 9,35 a $A$ & 11,05 a $A$ & 9,92 bc \\
\hline Esmeralda & 9,71 a $A$ & 11,81 a $A$ & 10,17 a $A$ & 8,94 a $A$ & 10,49 a $A$ & 11,84 a $A$ & $10,49 \mathrm{~b}$ \\
\hline Zoysia & 7,55 a A & 8,76 a $A$ & 9,43 a $A$ & 7,33 a $A$ & 9,63 a $A$ & 10,09 a $A$ & $8,80 \mathrm{c}$ \\
\hline Médias. & $10,2 \mathrm{~B}$ & $11,17 \mathrm{AB}$ & $11,14 \mathrm{AB}$ & $9,97 \mathrm{~B}$ & $10,2 \mathrm{AB}$ & $12,13 \mathrm{~A}$ & \\
\hline \multicolumn{8}{|c|}{$2^{2}$ ÉPOCA - Verão } \\
\hline & \multicolumn{6}{|c|}{ Substratos } & \multirow[b]{2}{*}{ Médias } \\
\hline Espécies & $A$ & $B$ & $\mathrm{C}$ & $\mathrm{D}$ & $E$ & $F$ & \\
\hline Santo Agostinho & 9,43 a $A$ & $12,32 \mathrm{a} \mathrm{A}$ & 11,98 a $A$ & 11,82 a $A$ & 10,68 a $A$ & 12,54 a $A$ & $11,46 a$ \\
\hline São Carlos & 8,84 a $A$ & 9,93 a $A$ & 9,18 a $A$ & 10,64 a $A$ & 9,86 a $A$ & 10,10 a $A$ & $9,76 \mathrm{~b}$ \\
\hline Bermudas & 7,17 a A & 8,61 a $A$ & 8,38 a $A$ & 7,86 a $A$ & 7,98 a $A$ & 8,61 a $A$ & $8,10 \mathrm{~cd}$ \\
\hline Esmeralda & 8,83 a $A$ & 8,55 a $A$ & 10,10 a $A$ & 9,57 a $A$ & 7,74 a A & 10,19 a $A$ & 9,16 bc \\
\hline Zoysia & 7,32 a $A$ & 8,00 a $A$ & $7,79 a \mathrm{~A}$ & 6,69 a $A$ & 8,23 a $A$ & 9,03 a $A$ & $7,84 \mathrm{~d}$ \\
\hline Médias & $8,32 \mathrm{~B}$ & $9,48 \mathrm{AB}$ & $9,48 \mathrm{AB}$ & $9,31 \mathrm{AB}$ & $8,90 A B$ & $10,09 \mathrm{~A}$ & \\
\hline
\end{tabular}

Médias seguidas de letras minúsculas iguais, nas colunas e letras maiúsculas iguais, nas linhas, nāo diferem entre si pelo teste de Tukey, ao nivel de $5 \%(\alpha \leq 0,05)$.

\subsubsection{Primeira e Segunda época}

\subsection{Espécies de gramas}

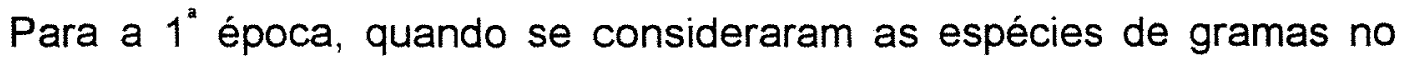
geral, a média da variedade Santo Agostinho foi significativamente maior que as demais, a média da variedade Zoysia foi significativamente menor e as médias das variedades São Carlos, Bermudas e Esmeralda são intermediárias. O mesmo ocorreu para a $2^{a}$ época. Lorenzi (1999) descreve a Santo Agostinho como uma grama que se multiplica facilmente por mudas obtidas de estolhos enraizados. Isto foi verificado no rápido enraizamento e crescimento durante o experimento, marcando diferença em relação às outras espécies. Plantas \& Flores (1971) a descreve como uma grama que não suporta secas, geadas ou invernos mais rigorosos o que condiz com os resultados do experimento em relação ao parâmetro comprimento de raiz, porque durante a primeira época de 
plantio as temperaturas oscilavam entre 11 e $18^{\circ} \mathrm{C}$, típicas de um clima ameno onde o fator temperatura não seria limitante. De acordo com isto, as temperaturas quentes e frias durante as duas épocas de cultivo não influenciaram o crescimento das gramas, portanto, por serem espécies diferentes diferem também no tempo de crescimento sendo uma característica fisiológica própria de cada espécie.

\subsubsection{Substratos}

Quando se consideraram substratos no geral, na $1^{2}$ época, a média do substrato $F$ foi significativamente maior que as médias dos substratos $A$ e $D$, enquanto que, na 2 época, a média do substrato $F$ foi significativamente maior apenas com relação à média do substrato $A$. $O$ fato do substrato $F$ apresentar os melhores resultados em relação aos outros para este parâmetro, demonstra uma resposta positiva das mudas de grama a presença de nutrientes em pequenas quantidades no substrato. $O$ registro fotográfico do resultado acima relatado pode se observado na figura $5 \mathrm{~F}$.

Uma melhor visualização dos resultados para a variável CMSR, em função das espécies de gramas e substratos, nas duas épocas, é dada pela Figura 1. 


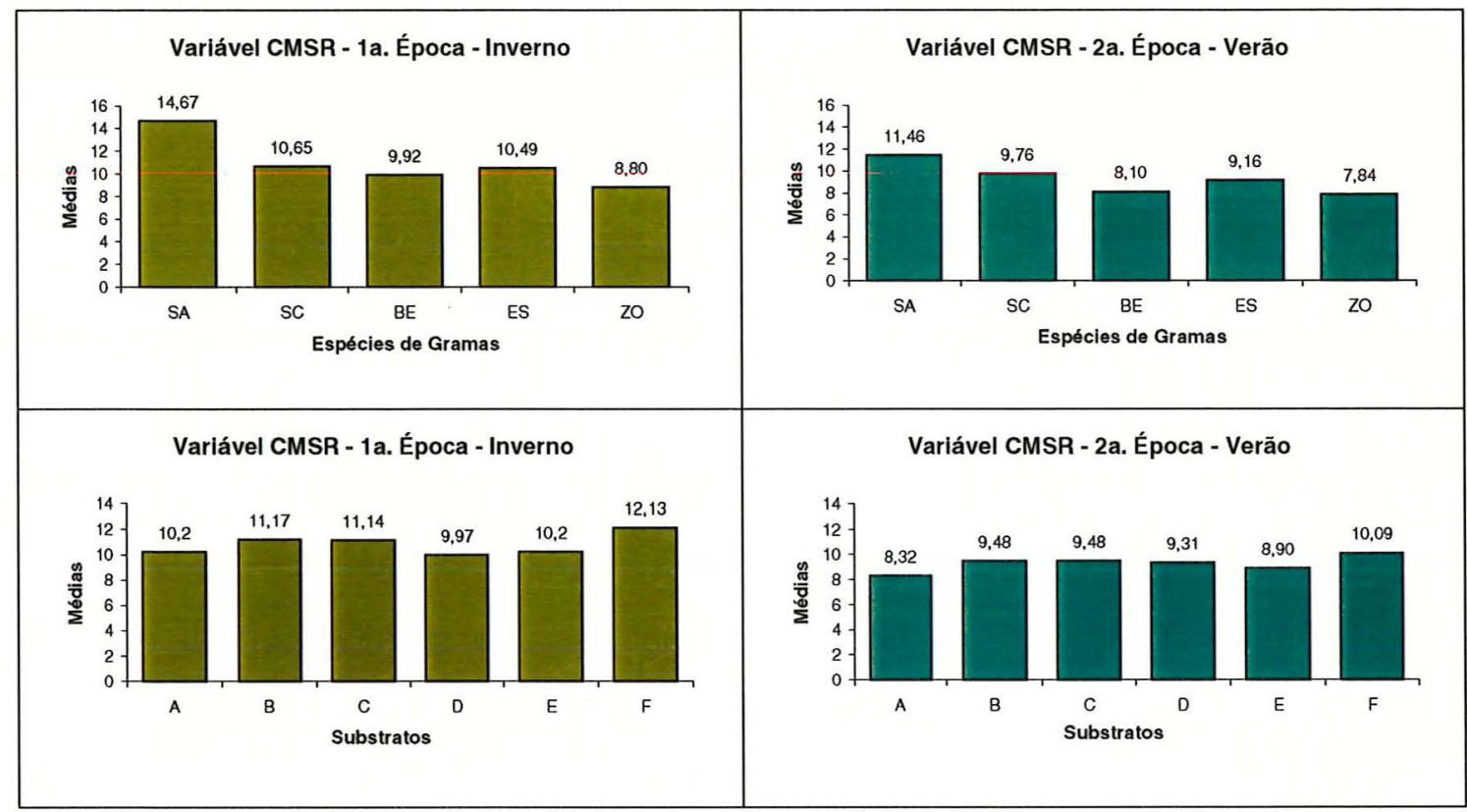

Figura 1 - Médias da variável comprimento do sistema radicular (CMSR) para as duas épocas em função das espécies de gramas e substratos.

\subsubsection{Volume de raiz}

A Tabela 7 mostra as médias originais e teste de Tukey para a variável VR, em função das espécies de gramas e substratos obtidas na $1^{a}$ época (inverno) e $2^{\text {a }}$ época (verão).

\subsubsection{Primeira época}

\subsection{Espécies de gramas}

$\mathrm{Na} 1^{a}$ época, a média da espécie Santo Agostinho foi significativamente maior que todas, com da exceção São Carlos que foi igual. As médias das espécies Esmeralda e Zoysia foram significativamente menores que as duas primeiras. Durante o experimento foram verificadas certas características próprias de cada espécie, entre elas a forma de crescimento. 
Tabela 7. Médias originais da variável volume de raízes (VR), para as duas épocas, em função das espécies de gramas e substratos.

\begin{tabular}{|c|c|c|c|c|c|c|c|}
\hline \multirow[b]{2}{*}{ Espécies } & \multicolumn{6}{|c|}{ Substratos } & \multirow[b]{2}{*}{ Médias } \\
\hline & A & $B$ & $\mathrm{C}$ & $D$ & $E$ & $F$ & \\
\hline Santo Agostinho & 11,28 a $A$ & 11,99 a $\mathrm{A}$ & 12,72 a $A$ & 13,34 a $A$ & 13,34 a $A$ & 12,39 a $A$ & $12,51 \mathrm{a}$ \\
\hline São Carlos & 13,65 a $A$ & 9,04 a A & 11,96 a $A$ & 12,19 a $A$ & 14,22 a $A$ & 11,05 a $A$ & $12,02 a b$ \\
\hline Bermudas & 8,24 a $A$ & 7,85 a $A$ & 11,41 a $A$ & 9,21 a $A$ & 13,55 a $A$ & 10,41 a $A$ & 10,11 bc \\
\hline Esmeralda & 8,37 a $A$ & 5,28 a $A$ & 12,34 a $A$ & 7,17 a $A$ & 10,84 a $A$ & 9,54 a $A$ & $8,92 \mathrm{c}$ \\
\hline Zoysia & 8,83 a A & 11,36 a $\mathrm{A}$ & 10,23 a $A$ & 6,77 a A & 11,52 a $\mathrm{A}$ & 9,89 a A & $9,77 \quad \mathrm{c}$ \\
\hline Médias & $10,07 \mathrm{BC}$ & $9,11 \mathrm{C}$ & $11,73 \mathrm{AB}$ & $9,74 \mathrm{BC}$ & $12,70 \mathrm{~A}$ & $10,66 \mathrm{AC}$ & \\
\hline \multicolumn{8}{|c|}{$2^{2}$ ÉPOCA - Verão } \\
\hline & \multicolumn{6}{|c|}{ Substratos } & \multirow[b]{2}{*}{ Médias } \\
\hline Espécies & $\mathrm{A}$ & $B$ & C & $\mathrm{D}$ & $E$ & $F$ & \\
\hline Santo Agostinho & 21,95 a $A$ & 21,03 a A & 21,89 a $A$ & 22,77 a A & 25,48 a $A$ & 22,69 a A & $22,63 \mathrm{a}$ \\
\hline São Carlos & 18,93 a $A$ & 21,09 a $A$ & 20,80 a $A$ & 20,80 a $\mathrm{A}$ & 23,01 a $A$ & 21,35 a $A$ & $21,00 a b$ \\
\hline Bermudas & 20,86 a $A$ & 22,35 a $A$ & 23,67 a $A$ & 20,91 a A & 22,22 a $A$ & 23,80 a $A$ & $22,30 \mathrm{ab}$ \\
\hline Esmeralda & 21,76 a $A$ & 20,51 a $A$ & 20,15 a $A$ & 20,63 a $A$ & 22,04 a A & 22,53 a $A$ & $21,27 a b$ \\
\hline Zoysia & 20,67 a A & 20,11 a A & 18,22 a A & 20,07 a A & 21,53 a $A$ & 23,12 a A & 20,62 b \\
\hline
\end{tabular}

Médias seguidas de letras minúsculas iguais, nas colunas e letras maiúsculas iguais, nas linhas, não diferem entre si pelo teste de Tukey, ao nivel de $5 \%(\alpha \leq 0,05)$.

Na grama Santo Agostinho foi observado abundante número de raizes finas e compridas, porém na grama São Carlos raízes abundantes, grossas e curtas. Nas duas observou-se um rápido desenvolvimento. A grama Zoysia tem uma escassa quantidade de raízes, sendo muito finas, e dificilmente ocupam o espaço total da célula, além de apresentar um lento enraizamento. Poderia se dizer que de acordo com estas descrições, e independentemente do efeito dos substratos, a forma de crescimento das raízes próprias de cada espécie, poderia ter influenciado no maior ou menor volume de raizes.

\subsection{Substratos}

Quando são considerados substratos, a média de volume de raiz do substrato $E$, foi significativamente maior que as demais. As médias de $A, C, D$ e $F$ foram intermediárias e a média do substrato $B$ foi significativamente menor. $O$ 
substrato $E$ é composto de vermiculita + esterco bovino curtido (2:1). Como toda matéria orgânica, o esterco bovino curtido e um material que melhora as características físicas do solo e de substratos, além de liberar nutrientes, sendo por esse motivo também utilizado como adubo. As boas características deste composto provavelmente influenciou no bom desenvolvimento das raizes.

\subsubsection{Segunda época (Verão)}

\subsection{Espécies de gramas}

Os resultados da segunda época foram semelhantes aos da primeira época. Quando se consideraram as espécies de gramas no geral, a média de volume de raiz da espécie Santo Agostinho foi significativamente maior que a média da espécie Zoysia; as médias das espécies São Carlos, Bermudas e Esmeralda foram intermediárias.

\subsection{Substratos}

Não ocorreu diferenças significativas entre as médias dos substratos.

$\mathrm{Na}$ produção de mudas, a mais importante diferença existente entre o cultivo no solo e no substrato é o volume das raízes.

A cultura plantada no solo, tem por $\mathrm{m}^{2}$ um volume disponível para as raízes de $500 \mathrm{~L}(50 \mathrm{~cm}$ de profundidade). Já o volume disponivel para as culturas feitas em bandejas, sacos ou vasos são bem menores ( 0,25 a 15L). Este volume pequeno traz conseqüências para a disponibilidade de água. No solo esta disponibilidade significa $30 \%$ do volume e em substrato $50-70 \%$.

Uma melhor visualização dos resultados para a variável VR, em função das espécies de gramas e substratos, nas duas épocas, é dada pela Figura 2. 


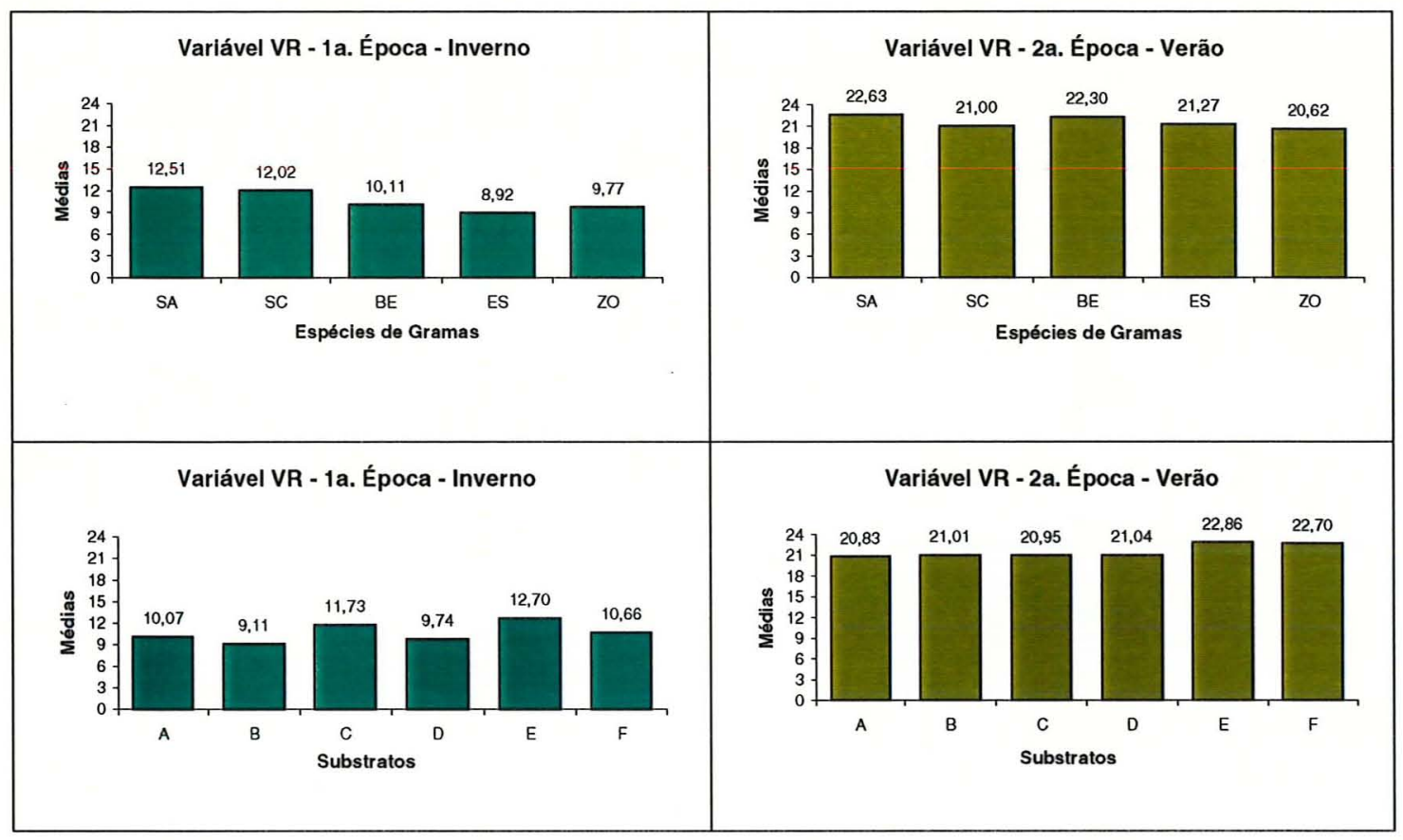

Figura 2 - Médias da variável volume de raiz (VR) para as duas épocas em função das espécies de gramas e substratos.

\subsubsection{Volume da parte aérea}

A Tabela 8 mostra as médias originais e teste de Tukey para a variável VPA, devidas às espécies de gramas e substratos obtidas na $1^{a}$ época (inverno) e $2^{\underline{a}}$ época (verão).

\subsubsection{Primeira época (Inverno)}

\subsection{Espécies de gramas}

$\mathrm{Na} 1^{a}$ época o resultado foi semelhante. Agora a espécie São Carlos se igualou estatisticamente a Santo Agostinho. Estas espécies se destacaram por seu rápido fechamento na bandeja. A grama São Carlos possui folhas abundantes e mais largas que as demais espécies. Cresce muito rápido quando as condições de umidade e temperatura do ar são favoráveis, o que acontece também com a grama Santo Agostinho. $O$ crescimento diferenciado, com folhas 
Tabela 8 - Médias originais da variável volume da parte aérea (VPA), para as duas épocas, em função das espécies de gramas e substratos.

\begin{tabular}{|c|c|c|c|c|c|c|c|}
\hline \multicolumn{8}{|c|}{$1^{a}$ ÉPOCA - Inverno } \\
\hline \multirow[b]{2}{*}{ Espécies } & \multicolumn{6}{|c|}{ Substratos } & \multirow[b]{2}{*}{ Médias } \\
\hline & A & $B$ & $\mathrm{C}$ & $D$ & $\bar{E}$ & $F$ & \\
\hline Santo Agostinho & 11,34 a $A$ & 13,75 a A & $11,50 \mathrm{a} A$ & 12,65 a $A$ & 14,35 a $A$ & 13,46 a $A$ & 12,84 a \\
\hline São Carl & 13,48 a $A$ & 8,66 a A & 11,81 a $A$ & 12,40 a A & 14,70 a $\mathrm{A}$ & 11,35 a $A$ & $12,07 a b$ \\
\hline & 8,36 a $A$ & 7,06 a A & 11,52 a $A$ & 8,86 a $\mathrm{A}$ & 16,45 a $\mathrm{A}$ & 11,39 a $A$ & $10,61 \mathrm{bc}$ \\
\hline & 8,84 a A & 6,30 a A & 11,34 a $A$ & 6,68 a $A$ & 12,76 a $A$ & 9,98 a $A$ & $9,32 \mathrm{~cd}$ \\
\hline Zoy & 8,19 a $A$ & 8,50 a A & 9,01 a $A$ & 6,51 a A & 8,73 a $A$ & 8,76 a $A$ & 8,28 \\
\hline & $10,04 \mathrm{~B}$ & $8,86 \mathrm{~B}$ & $11,04 \mathrm{AB}$ & $9,42 \mathrm{~B}$ & $13,40 \mathrm{~A}$ & $10,99 \mathrm{AB}$ & \\
\hline \multicolumn{8}{|c|}{$2^{2}$ ÉPOCA - Verão } \\
\hline & \multicolumn{6}{|c|}{ Substratos } & \multirow[t]{2}{*}{ Médias } \\
\hline Esp & $A$ & $B$ & C & $D$ & $E$ & $\mathrm{~F}$ & \\
\hline Santo Agostinho & 22,80 a $\mathrm{A}$ & 21,56 a A & 23,88 a $A$ & 24,82 a $A$ & 27,48 a $A$ & 23,61 a $A$ & 24,02 a \\
\hline São & 19,10 a $A$ & 21,02 a $A$ & 20,50 a $A$ & 20,00 a A & 24,34 a A & 23,47 a $A$ & $1 \mathrm{bc}$ \\
\hline Bermuda & 21,49 a $\mathrm{A}$ & 22,04 a $A$ & 24,04 a A & 21,13 a $A$ & 23,51 a $A$ & 25,68 a $A$ & $22,98 a b$ \\
\hline Esmeralda & 21,72 a $A$ & 21,37 a $A$ & 19,73 a $A$ & 20,55 a $A$ & 23,14 a $\mathrm{A}$ & 24,73 a A & $21,87 b c$ \\
\hline Zoysia & 19,65 a $A$ & 19,89 a $A$ & 16,74 a $A$ & 20,61 a A & 24,87 a $A$ & 22,69 a A & $20,74 \mathrm{c}$ \\
\hline Médias & $20,95 \mathrm{~B}$ & $21,18 \mathrm{~B}$ & $20,98 \mathrm{~B}$ & $21,42 \mathrm{~B}$ & $24,67 A$ & $24,04 A$ & \\
\hline
\end{tabular}

Médias seguidas de letras minúsculas iguais, nas colunas, letras maiúsculas iguais, nas linhas não diferem entre si pelo teste de Tukey, ao nivel de $5 \%(\alpha \leq 0,05)$.

abundantes, poderia ter favorecido o volume da parte aérea. A grama Bermuda ficou diferente com o menor volume da parte aérea.

\subsection{Substratos}

Quando são considerados substratos, na $1^{2}$ época, a média do substrato $\mathrm{E}$ foi significativamente maior que as demais, exceção feita aos substratos $\mathrm{Fe}$ C; a média do substrato $B$ foi a menor. 


\subsubsection{Segunda época}

\subsection{Espécies de grama}

Para a Segunda época o resultado foi semelhante a primeira época. Quando se consideraram as espécies de gramas, a média da espécie SA foi significativamente maior que as demais (com exceção da $\mathrm{BE}$ ), a média da espécie ZO foi significativamente menor que as demais (igual somente a SC e ES).

\subsection{Substratos}

Considerando substratos, as médias $E$ e $F$ foram significativamente maiores, as médias dos substratos $A, B, C$ e $D$ foram significativamente menores, conforme pode ser observado nas figuras 4 e 5 .

Uma melhor visualização dos resultados para a variável VPA, em função das espécies de gramas e substratos, nas duas épocas, é dada pela Figura 6.

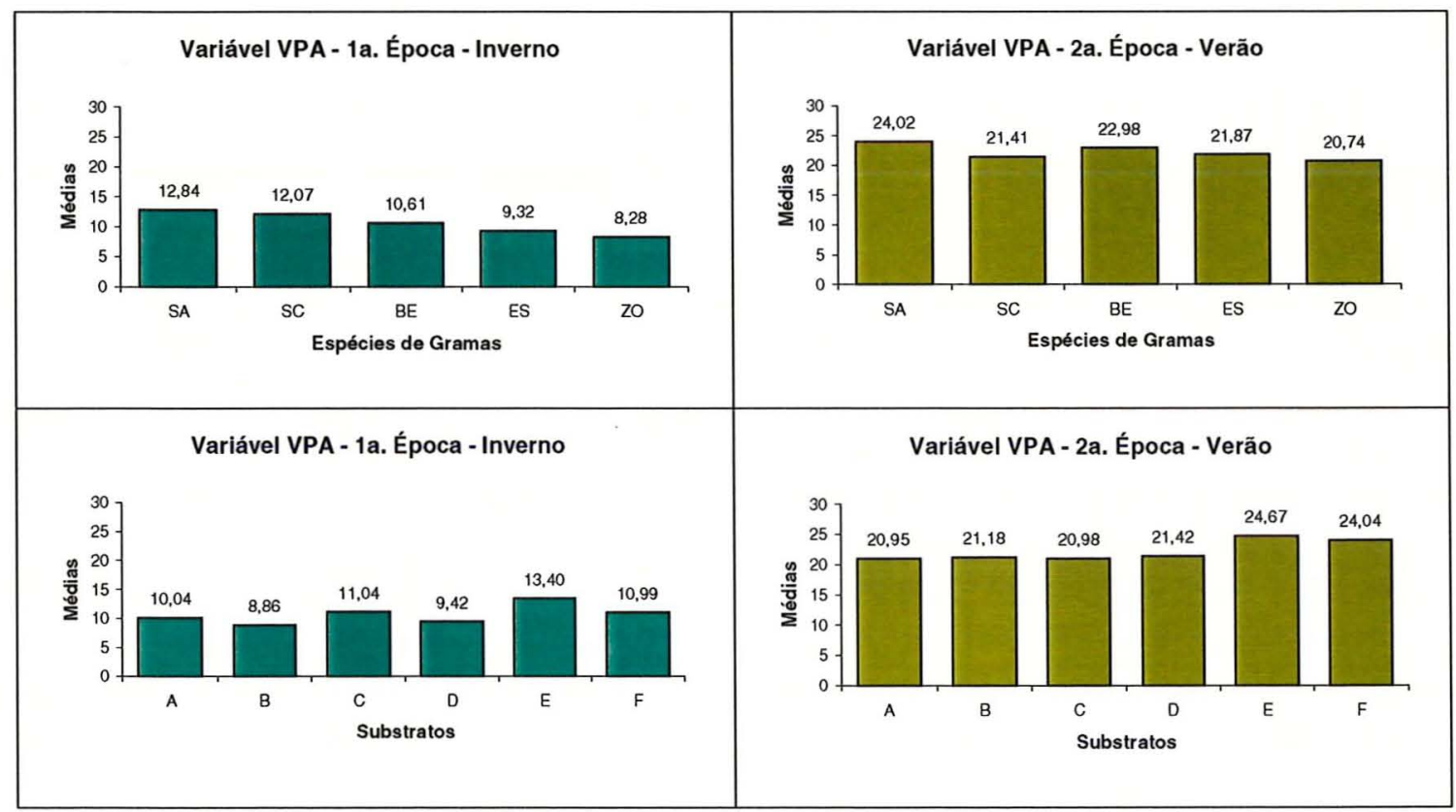

Figura 3 - Médias da variável volume da parte aérea (VPA) para as duas épocas em função das espécies de gramas e substratos. 

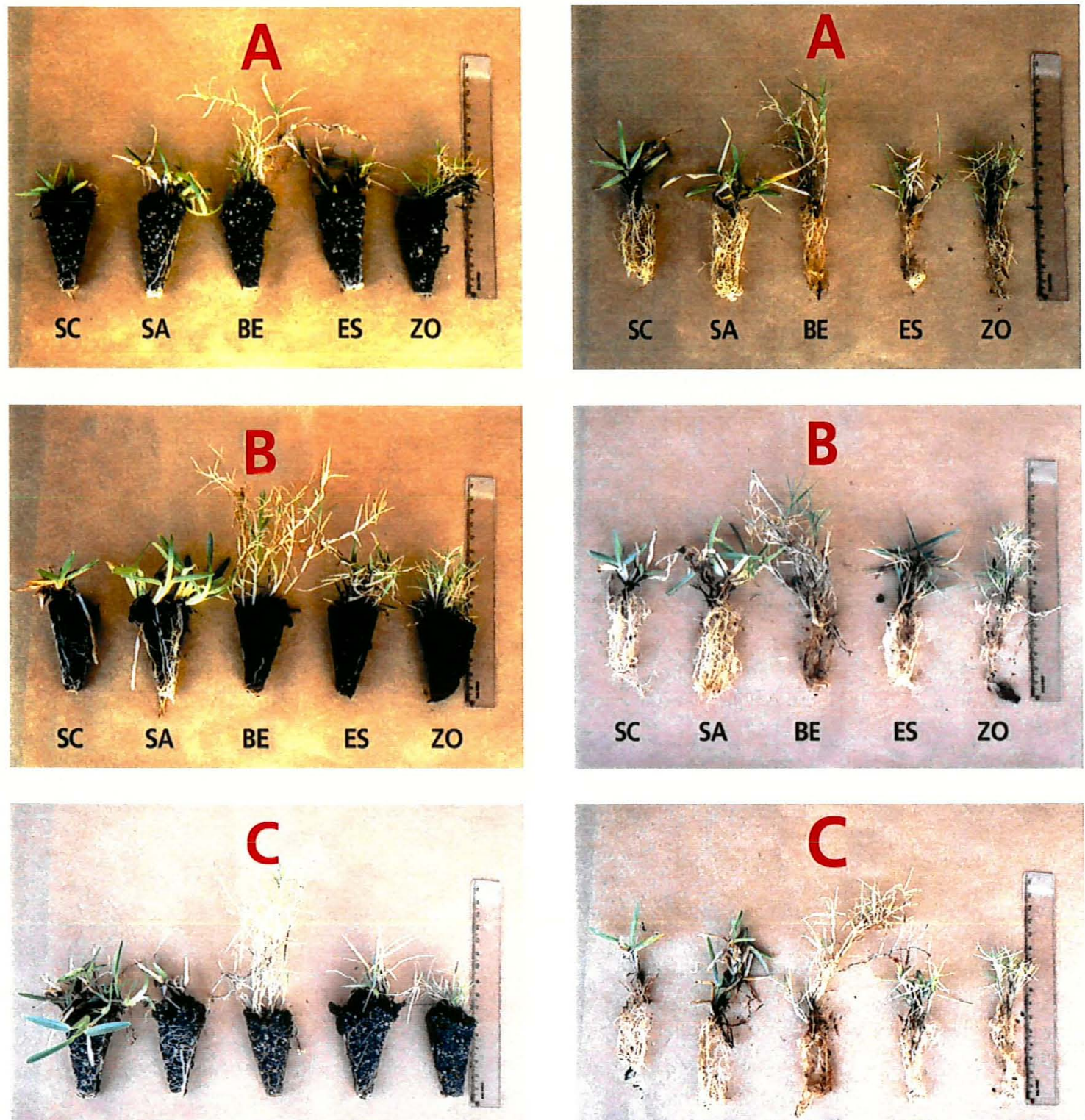

SC SA BE ES ZO

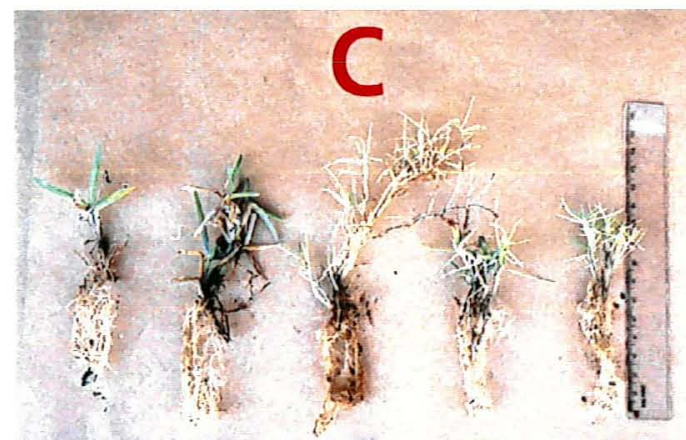

SC SA BE ES ZO

Figura 4 - Espécies de grama São Carlos (SC)Santo Agostinho (SA), Bermudas (BE), Esmeralda (ES) e Zoysia (ZO) testadas nos substratos $A, B, C$, na segunda época de cultivo (verão). 

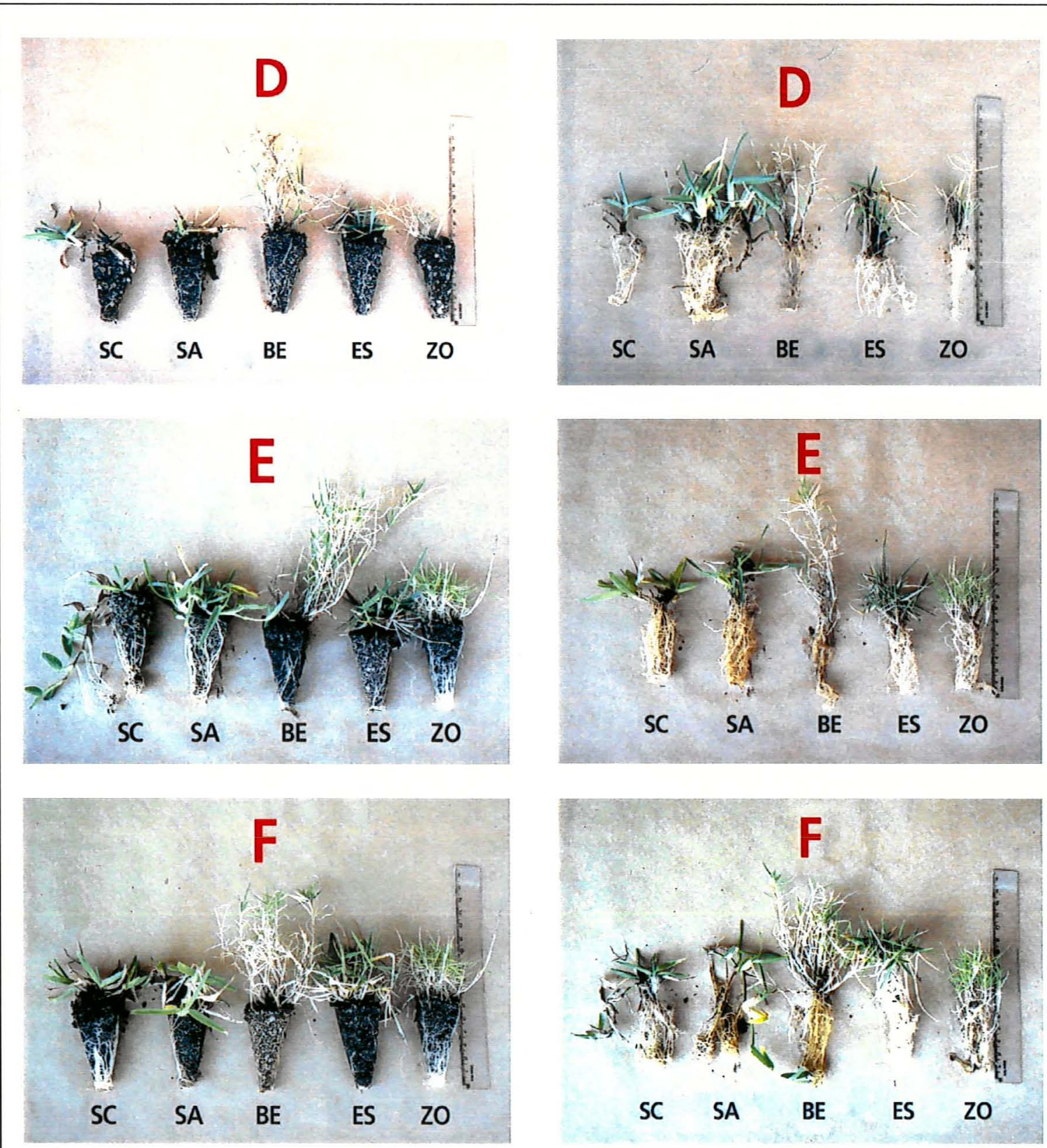

Figura 5 - Espécies de gramas São Carlos (SC), Santo Agostinho (SA), Bermudas (BE), Esmeralda (ES) e Zoysia (ZO) testadas nos substratos D, E, F, na segunda época de cultivo (verão). 


\subsubsection{Massa seca do sistema radicular (MSR)}

A Tabela 9 mostra as médias originais e teste de Tukey para a variável (massa seca radicular) MSR, das espécies de gramas e misturas de substratos obtidas na $1^{2}$ época (inverno) e $2^{2}$ época (verão).

Tabela 9 - Médias originais da variável MSR, para as duas épocas, em função das espécies de gramas e substratos

\begin{tabular}{|c|c|c|c|c|c|c|c|}
\hline \multicolumn{8}{|c|}{$1^{\circ}$ EPOCA - Inverno } \\
\hline \multirow[b]{2}{*}{ Espécies } & \multicolumn{6}{|c|}{ Substratos } & \multirow[b]{2}{*}{ Médias } \\
\hline & $\bar{A}$ & $\mathrm{~B}$ & $\mathrm{C}$ & $D$ & $E$ & $F$ & \\
\hline Santo Agostinho & 0,69 a $A$ & 0,67 a $A$ & 0,68 a $A$ & 0,62 a $A$ & 0,91 a $A$ & 0,62 a $A$ & $0,70 \mathrm{a}$ \\
\hline São Carios & 0,57 a $A$ & 0,66 a $\mathrm{A}$ & 0,65 a $A$ & 0,72 a $A$ & 0,73 a A & 0,76 a $A$ & $0,68 a b$ \\
\hline Bermudas & 0,63 a $A$ & 0,55 a A & 0,74 a A & 0,64 a A & 0,73 a $A$ & 0,78 a A & $0,68 \mathbf{a b}$ \\
\hline Esmeralda & 0,65 a $A$ & 0,58 a $A$ & 0,51 a A & 0,60 a A & 0,52 a $A$ & 0,59 a $A$ & $0,57 \mathrm{bc}$ \\
\hline Zoysia & 0,45 a $A$ & 0,55 a $A$ & 0,47 a $A$ & 0,46 a $A$ & 0,54 a A & 0,64 a A & $0,52 \mathrm{c}$ \\
\hline Médias & $0,60 \mathrm{~A}$ & $0,60 \mathrm{~A}$ & $0,61 \mathrm{~A}$ & $0,61 \mathrm{~A}$ & $0,69 \mathrm{~A}$ & $0,68 \mathrm{~A}$ & \\
\hline \multicolumn{8}{|c|}{$2^{2}$ ÉPOCA - Verão } \\
\hline & \multicolumn{6}{|c|}{ Substratos } & \multirow[b]{2}{*}{ Médias } \\
\hline Espécies & A & $\mathrm{B}$ & $\mathrm{C}$ & $\bar{D}$ & $E$ & $\bar{F}$ & \\
\hline Santo Agostinho & 1,17 a $A$ & $0,63 \mathrm{~b} \mathrm{~A}$ & 0,86 a $A$ & 0,86 a $A$ & 0,97 a A & 0,84 a A & $0,89 \mathrm{a}$ \\
\hline São Carlos & $0,41 \mathrm{bC}$ & 1,31 a $A$ & 0,51 a C & $0,68 \mathrm{aBC}$ & $0,98 \mathrm{aABC}$ & $1,17 \mathrm{aAB}$ & $0,84 a$ \\
\hline Bermudas & $0,72 a b A$ & $0,65 \mathrm{~b} \mathrm{~A}$ & 0,58 a $A$ & 0,49 a A & 0,98 a $A$ & 0,72 a $A$ & $0,69 a b$ \\
\hline Esmeralda & $0,65 a b A$ & $0,48 \mathrm{~b} \mathrm{~A}$ & 0,72 a $A$ & 0,58 a $A$ & 0,89 a $A$ & 1,01 a $A$ & $0,72 a b$ \\
\hline Zoysia & $0,47 \mathrm{bABC}$ & $0,44 \mathrm{bBC}$ & $0,43 a B C$ & 0,33 a $C$ & $1,03 a \mathrm{~A}$ & $0,98 \mathrm{aAB}$ & $0,61 \mathrm{~b}$ \\
\hline Médias & $0,68 \mathrm{C}$ & $0,70 \mathrm{BC}$ & $0,62 \mathrm{C}$ & $0,59 \mathrm{C}$ & $0,97 \mathrm{~A}$ & $0,94 \mathrm{AB}$ & \\
\hline
\end{tabular}

Médias seguidas de letras minúsculas iguais, nas colunas, e letras maiúsculas iguais, nas linhas não diferem entre si pelo teste de Tukey, ao nivel de $5 \%(\alpha \leq 0,05)$

O parâmetro massa seca foi aquele cuja análise dos dados revelou, dentre todos os parâmetros estudados, as maiores diferenças estatisticamente significativas entre os substratos e as espécies. A matéria seca do ponto de vista bioquímico e fisiológico, é o resultado da somatória dos processos metabólicos que contribuem para a produção como fotossíntese, a translocação, o armazenamento dos assimilados (Beringer, 1982). Portanto, uma planta que esteja numa situação ideal de quantidade e qualidade de nutrientes, poderá realizar todos os processos metabólicos e assim alcançar 
altos niveis de crescimento e de formação de novas e maiores estruturas orgânicas (Gonçalves, 1992).

\subsubsection{Primeira época (Inverno)}

\subsection{Espécies de gramas}

$\mathrm{Na} 1^{2}$ época, quando são consideradas as espécies de gramas, a média massa seca da raiz da espécie Santo Agostinho, foi a maior, não diferindo da São Carlos nem da Bermudas. A média da espécie Zoysia foi significativamente menor, não diferindo de ES. As gramas Santo Agostinho, São Carlos e Bermudas têm características similares pois possuem estolhos abundantes o que proporciona um rápido crescimento, quando as condições ambientais são favoráveis (Itograss, 1997). Isto foi observado durante o experimento, pois as gramas que obtiveram as maiores médias apresentaram um rápido enraizamento, apesar das temperaturas serem baixas nesta época. A utilização de casa de vegetação e o sistema de irrigação automatizado poderia ter favorecido seu bom desenvolvimento. Já para Zoysia, o crescimento é muito lento (Lorenzi, 1999), apesar de apresentar estolhos abundantes (Itograss, 1997). Esta espécie no dia da avaliação não apresentava um bom enraizamento como as demais. As raízes eram poucas e muito finas, sendo dificil por esse motivo retirar o substrato.

\subsection{Substratos}

Quando se consideraram substratos, na $1^{2}$ época, confirmando os resultados da Tabela 1 , não foi evidenciada pelo teste de Tukey diferenças entre eles. 


\subsubsection{Segunda época (Verão)}

\subsection{Espécies de gramas}

$\mathrm{Na} 2{ }^{2}$ época houve interação significativa entre as espécies de gramas e misturas de substratos, sendo por esse motivo, necessário verificar as espécies dentro de cada substrato.

No substrato $A$, a média da espécie Santo Agostinho foi a maior, não diferindo porém da Bermudas e Esmeralda; as médias de São Carlos e Zoysia foram as menores conforme mostra a figura 4A. Este substrato contendo vermiculita + casca de arroz carbonizada (2:1) foi também utilizado por Gonçalves (1992) na produção de mudas de calanchoe, sendo os resultados não significativos com relação a matéria seca. De acordo com seus resultados de análise do substrato o pH foi 6,25, considerado como um nivel alto. Segundo Richter (1983) a espécie Santo Agostinho exige um solo com pH entre 6 e 7, fator que poderia ter sido proporcionado por este substrato se consideramos as caraterísticas dos componentes. De forma geral a vermiculita tem um pH 6,4, e a casca de arroz carbonizada é considerada ligeiramente alcalina (Minami, 1995). Pode-se observar também que nesta mistura a vermiculita proporcionou retenção de água porém não o suficiente, porque nos intervalos de irrigação o substrato encontrava-se geralmente mais seco com relação aos outros. Fato que não dever ter sido muito favorável para a espécie Zoysia manifestando-se com pouco crescimento. Já para espécie São Carlos tendo a média mais baixa, apresentou os sintomas característicos de falta de água como amarelamento. $\dot{E}$ importante explicar, que os tempos e intervalos de irrigação tiveram que ser mudados em varias oportunidades, porque as necessidades de água para cada tratamento eram diferentes. Contudo, foi dificil encontrar o melhor, que possa satisfazer com precisão, dado que alguns substratos precisavam de maior quantidade de água, devido a drenagem mais rápida, e outros menor 
quantidade por reter uma boa parte. Algumas espécies se desenvolvem em substratos mais úmidos e outras já não se adaptam ao excesso de água.

No substrato B, a média espécie São Carlos foi significativamente maior que as demais. Este substrato contém as misturas (casca de pinus + casca de eucaliptus) + turfa + casca de arroz (1:1:1). Dematte (1996) num trabalho realizado com orquídeas epifitas, observou que $\mathrm{opH}$ da casca de eucaliptus variava de 4 até 4,7. A turfa caracteriza-se também por baixo valor de $\mathrm{pH}$ e excessiva capacidade de retenção de água, no entanto, a casca de arroz carbonizada é ligeiramente alcalina, e favorece a drenagem (Kampf, 1993). Portanto, as misturas destes materiais poderiam ter proporcionado condições desfavoráveis para espécies que são intolerantes a acidez e favorecido o crescimento da espécie São Carlos. Esta grama adapta-se bem em solos levemente ácidos, ou seja na faixa de 4 a 7 (Richter, 1983), além de ser nativa de lugares úmidos (Lorenzi, 1999) o que ajudou também seu crescimento.

Nos substratos C, D, E e F não ocorreram diferenças significativas entre as médias das espécies de gramas, portanto o uso de qualquer um destes materiais, será indiferente no maior o menor crescimento das espécies.

\subsection{Substratos}

$\mathrm{Na} 2^{2}$ época houve interação significativa entre as médias das espécies de gramas e substratos, sendo por esse motivo, necessário verificar substratos dentro de cada espécies de gramas.

Nas espécies Santo Agostinho, Bermudas, e Esmeralda não ocorreram diferenças significativas entre as médias de massa seca de raiz dos substratos. A grama Bermuda tem hábitos rasteiros e propaga-se rápida e vigorosamente (Richter, 1983) embora seja muito macia, regenera-se rapidamente quando submetida a maus-tratos Já as gramas Santo Agostinho assim como a Esmeralda crescem rápida e vigorosamente, principalmente nos meses quentes ((Itograss, 1997), fator que poderia ter favorecido o crescimento, independentemente do substrato. 
Também nos resultados pode-se observar que as gramas Santo Agostinho e Bermudas apresentaram as maiores médias com os substratos $A$ e $E$. O substrato $E$ composto de esterco bovino curtido e vermiculita na proporção (1:2) favoreceu o crescimento de todas as espécies de gramas. $A$ grama Esmeralda com o substrato $\mathrm{F}$ obteve a melhor média.

Na espécie São Carlos, a média do substrato $B$ foi a maior ( não diferindo apenas do $E$ e $F$ ); as médias de $A$ e $C$ foram as menores. Este resultado concorda com Gonçalves (1992) na produção de mudas de calanchoe, apresentando maior massa seca da raiz, utilizando substrato composto por casca de arroz carbonizada + vermiculita (1:2). Já para o substrato $C$ (casca de pinus + turfa + vermicullita (2:1:1) os resultados obtidos não concordam com Lemaire et al. (1988) onde estudaram produtos a base de fibra de pinheiro e verificaram um bom desempenho desses produtos em mistura com turfa para 0 cultivo de plantas ornamentais em vasos.

Na espécie Zoysia, a média do substrato $E$ foi a maior (não diferindo de A e F) conforme mostra a figura 7E. Tullio et.al (1986) usando diferentes substratos na germinação e formação de mudas de pimentão, testou esterco bovino e verificou que o substrato a base deste componente foi considerado ótimo para formação das mudas, sendo assim de relevante importância os nutrientes existentes no esterco. A média do substrato $D$ vermicullita + casca de Eucalyptus (2:1) foi a menor e pode ser observado na figura 7D. A combinação destes materiais que caracterizam-se por possuir uma alta capacidade de retenção de água, proporcionou excesso de água no substrato o que talvez tenha inibido o desenvolvimento das raízes da espécie Zoysia. Kanashiro (1999) avaliando os efeitos de substratos produção de mudas de Aechmea fasciata utilizou casca de Eucalyptus em mistura com turfa e perlita na proporção $8: 1: 1$, e também obteve as menores médias no parâmetro massa seca foliar.

Uma melhor visualização dos resultados para a variável MSR, em função das espécies de gramas e substratos, nas duas épocas, é dada pela Figura 6. 


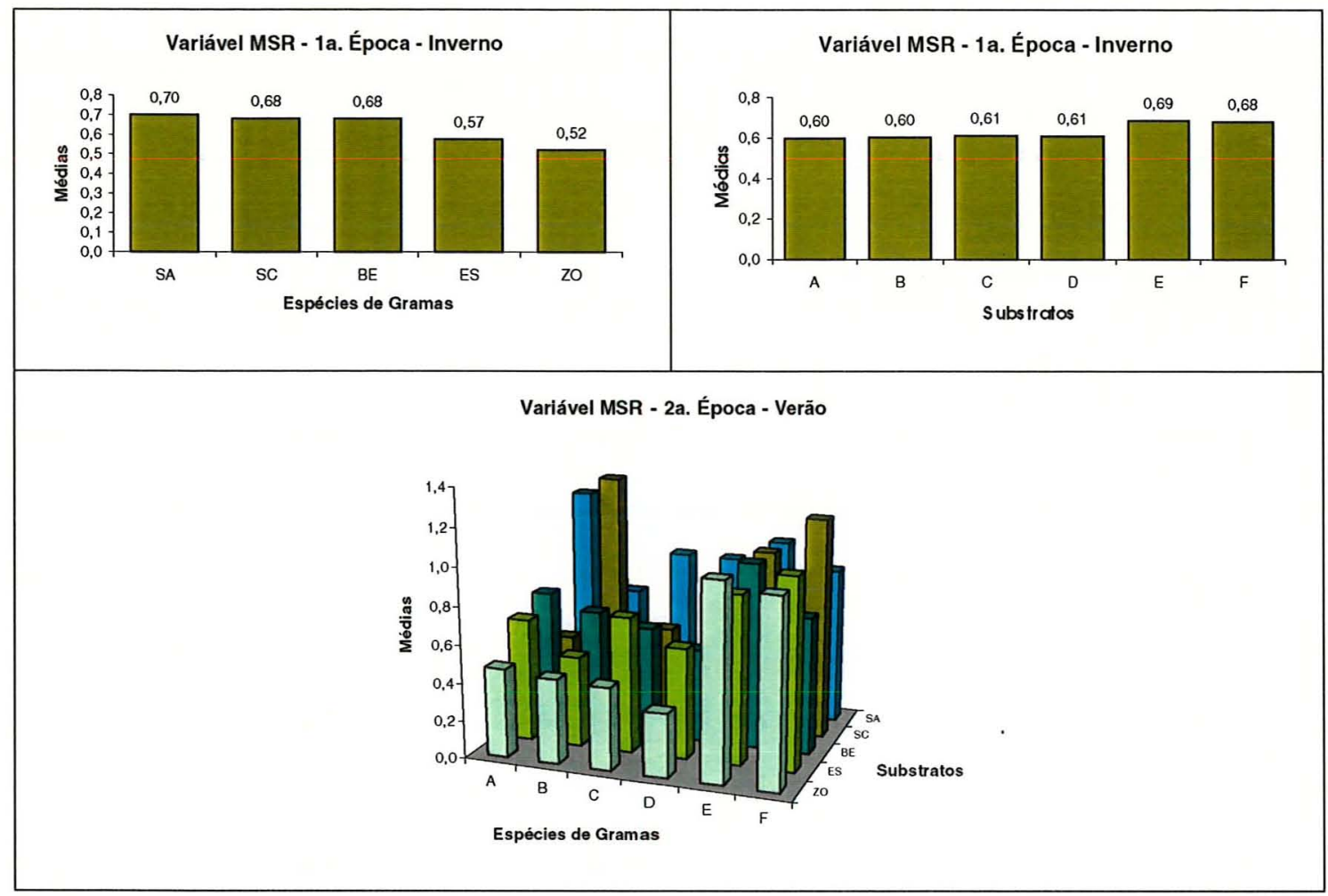

Figura 6 - Médias da variável MSR para as duas épocas em função das espécies de gramas e substratos.

\subsubsection{Massa seca da parte aérea (MSPA)}

A Tabela 10 mostra as médias originais e teste de Tukey para a variável MSPA, devidas às espécies de gramas e substratos obtidas na $1^{\text {a época }}$ (inverno) e $2^{2}$ época (verão).

\subsubsection{Primeira época (Inverno)}

\subsection{Espécies de gramas}

$\mathrm{Na} 1^{a}$ época, quando se consideraram as espécies de gramas no geral, a média da espécie Santo Agostinho e Bermudas foram significativamente maiores que as demais. Estas espécies não suportam temperaturas extremas, 
Tabela 10. Médias originais da variável massa seca da parte aérea (MSPA), para as duas épocas, em função das espécies de gramas e substratos.

\section{$1^{2}$ ÉPOCA - Inverno}

\begin{tabular}{|c|c|c|c|c|c|c|c|}
\hline \multirow{2}{*}{ Espécies } & \multicolumn{6}{|c|}{ Substratos } & \multirow{2}{*}{ Médias } \\
\hline & A & $\mathrm{B}$ & C & D & $E$ & $F$ & \\
\hline Santo Agostinho & 0,83 a $A$ & 0,76 a A & 0,78 a A & 0,76 a $A$ & 1,09 a $A$ & 0,84 a $A$ & $0,85 a$ \\
\hline São Carlos & 0,57 a $A$ & 0,65 a A & 0,64 a $A$ & 0,66 a $A$ & 0,82 a $A$ & 0,84 a $A$ & $0,70 \mathrm{~b}$ \\
\hline Bermudas & 0,93 a $A$ & 0,75 a $A$ & 0,97 a A & 0,77 a $A$ & 0,87 a A & 1,13 a $A$ & $0,90 \mathrm{a}$ \\
\hline Esmeralda & 0,67 a A & 0,63 a A & 0,60 a $A$ & 0,70 a $A$ & 0,70 a $A$ & 0,81 a $A$ & $0,68 \mathrm{~b}$ \\
\hline Zoysia & 0,51 a $\mathrm{A}$ & 0,65 a A & 0,51 a A & 0,54 a A & 0,73 a $A$ & 0,79 a A & $0,62 \mathrm{~b}$ \\
\hline Médias & $0,70 \mathrm{BC}$ & $0,69 \mathrm{C}$ & $0,70 \mathrm{BC}$ & $0,69 \mathrm{C}$ & $0,84 \mathrm{AB}$ & $0,88 \mathrm{~A}$ & \\
\hline \multicolumn{8}{|c|}{$2^{2}$ EPOCA - Verão } \\
\hline & \multicolumn{6}{|c|}{ Substratos } & \\
\hline Espécies & $\bar{A}$ & $\bar{B}$ & $\bar{C}$ & $D$ & $E$ & $F$ & Médias \\
\hline Santo Agostinho & $1,18 \mathrm{aAB}$ & 0,84 b B & $0,96 \mathrm{aAB}$ & $1,03 \mathrm{aAB}$ & $1,13 \mathrm{bAB}$ & $1,53 \mathrm{aA}$ & $1,11 \mathrm{a}$ \\
\hline São Carlos & $0,45 \mathrm{~b} \mathrm{C}$ & 1,67 a $A$ & $0,60 \mathrm{aBC}$ & $0,67 a b c$ & $1,1 \mathrm{abAB}$ & 1,42 ab $A$ & $1,00 \mathrm{a}$ \\
\hline Bermudas & $0,93 a b B$ & 1,00 b $B$ & 0,89 a $B$ & $0,79 a b B$ & 1,76 a $A$ & 1,61 a $A$ & $1,16 a$ \\
\hline Esmeralda & $0,99 a b A$ & 0,75 b A & 0,86 a $A$ & $0,88 a b A$ & $1,30 \mathrm{ab} A$ & $0,94 \mathrm{~b} \mathrm{~A}$ & $0,95 a b$ \\
\hline Zoysia & $0,54 \mathrm{~b} \mathrm{C}$ & $0,58 \mathrm{bBC}$ & 0,54 a C & $0,36 \mathrm{bC}$ & $1,18 \mathrm{abB}$ & 1,20 ab A & $0,73 \mathrm{~b}$ \\
\hline Médias & $0,82 \mathrm{~B}$ & $0,97 \mathrm{~B}$ & $0,77 \mathrm{~B}$ & $0,75 \mathrm{~B}$ & $1,31 \mathrm{~A}$ & $1,34 \mathrm{~A}$ & \\
\hline
\end{tabular}

Médias seguidas de letras minúsculas iguais, nas colunas, e letras maiúsculas iguais, nas linhas não diferem entre si pelo teste de Tukey, ao nível de $5 \%(\alpha \leq 0,05)$.

mas toleraram baixas temperaturas de até $10^{\circ} \mathrm{C}$ o que aconteceu na época do experimento. Em casa de vegetação as mudas ficaram protegidas dos dias mais frios desta estação o que conseqüentemente favoreceu o crescimento. Segundo Langhans (1980), a razão principal da construção de casa de vegetação é o cultivo de plantas fora de estação. Os fatores que influenciam no desevenvolvimento das culturas podem ser controlados dentro deste ambiente. (Mastalerz, 1977).

De acordo com os resultados, o cultivo em ambiente protegido, poderia ter favorecido o crescimento de todas as espécies. Ficaram protegidas das adversidades climáticas como baixas temperaturas no inverno e chuvas excessivas no verão. Também o sistema de irrigação proporcionou a água que seria necessária nos meses secos e frios do inverno e de muito calor no verão. 


\subsection{Substratos}

Quando se consideraram substratos, a média do substrato $F$ foi a maior, não diferindo apenas de $E$; as médias dos substratos $B$ e $C$ foram as menores (iguais entre si).

\subsection{Segunda época (Verão)}

\subsection{Espécies de gramas}

$\mathrm{Na} 2$ época houve interação significativa entre as espécies de gramas e substratos, sendo por esse motivo, necessário verificar as espécies dentro de cada substrato.

No substrato $A$, a média da massa seca da parte aérea da espécies Santo Agostinho foi maior (não diferindo de Bermudas e Esmeralda) ; Zoysia e São Carlos apresentaram as menores médias. A casca de arroz carbonizada em mistura com vermiculita na proporção (1:2) apresenta um espaço poroso total de $145,00 \mathrm{~mL}$ segundo a análise física realizada por Gonçalves (1992). Isto proporcionaria ao sistema radicular uma intensa possibilidade de trocas gasosas e fácil acesso ao oxigênio além de favorecer um ótimo desenvolvimento radicular. Desta forma poderia se explicar as excelentes médias obtidas com este substrato. No entanto, a casca de arroz carbonizada apresenta baixa densidade, o que constitui num serio problema para a utilização como substrato. As bandejas preenchidas, principalmente as de plástico, ficam muito leves e podem com um simples contato, serem derrubadas ou quebradas. Também ressecam-se mais facilmente devido a sua alta capacidade de drenagem, o que vem a exigir maior número de irrigações. Porém, tendo os substratos pesquisados recebidos as mesmas quantidades de água que os demais, parece ter sido suficiente, a ponto de terem apresentado bom resultado nestas espécies. As espécies Zoysia e São Carlos não suportam secas e como este substrato resseca-se mais rápido que os outros, deve ter influenciado no desenvolvimento. 
No substrato B, a média da espécie São Carlos foi significativamente maior que as demais. Este substrato apresentou uma alta capacidade de retenção de água, tanto assim que em alguns dias encontrava-se encharcado. Pelo que se pode observar a espécie São Carlos não tolerou substratos de fácil drenagem, produzindo, nessas circunstancias, amarelamento das folhas. Por esse motivo desenvolveu-se melhor num substrato que proporcionou maior umidade.

No substrato $C$ não houve diferença significativa entre as médias das espécies de gramas. No entanto, a espécie Santo Agostinho apresentou a maior média.

No substrato D, a média da espécie Santo Agostinho foi a maior, somente diferindo de Zoysia que foi a menor. Este substrato caracterizou-se também pela alta capacidade de retenção de água, fato que não favoreceu as espécies que ficaram com as menores médias.

No substrato $E$, a média da espécie Bermudas foi a maior, só diferindo de Santo Agostinho, a menor; as médias das espécies São Carlos, Esmeralda e Zoysia foram intermediárias. Visualmente todas apresentaram um bom desenvolvimento, mas com a espécie Bermudas, aos 30 dias após o plantio, observou-se que as mudas já poderiam estar prontas para o transplante no campo, fato que não aconteceu com os demais substratos na mesma espécie. Gonçalves (1992) obteve os melhores resultados com mudas de calanchoe quando nos substratos utilizados, a proporção de matéria orgânica em relação a vermiculita era menor. Minami (1980) recomenda que um substrato para o cultivo de plantas não deve apresentar teor elevado de matéria orgânica, a fim de não causar problema às plantas que irão ser cultivadas.

No substrato $F$, a média da espécie Bermudas foi a maior, só diferindo da Esmeralda, a menor; as médias de Santo Agostinho, São Carlos e Zoysia foram intermediárias. Este substrato também apresentou excelentes resultados. Aos 30 dias após o plantio as mudas das espécies Bermudas, São Carlos, Santo Agostinho e Zoysia apresentaram folhas de cor verde intenso e com um 
sistema radicular perfeitamente formado. Resultado que não condiz com Salvador (1995) testando substratos, entre eles o Plantmax para samambaia matogrossense produziu plantas de qualidade inferior já que elas precisam de substratos com capacidade de drenagem maior.

\subsection{Substratos}

$\mathrm{Na} 2{ }^{a}$ época houve interação significativa entre as espécies de gramas e substratos, sendo por esse motivo, necessário verificar substratos dentro de cada espécie de grama.

Nas espécies Santo Agostinho, a média do substrato $F$ foi a maior, diferindo apenas de $B$, a menor. As médias de $A, C, D$ e $E$ foram intermediárias. $O$ substrato $F$ que representa o Plantmax está composto a base de matéria orgânica e vermiculita expandida, possuindo nutrientes suficientes para o arranque inicial das mudas. Esse fator favoreceu o bom desempenho de quase todas as espécies.

Na espécie São Carlos, a média do substrato B foi a maior, diferindo apenas de A que foi a menor, confirmando assim com os resultados de MSR

$\mathrm{Na}$ espécie Bermudas e Zoysia, a média do substrato $E$ e $F$ foram significativamente maiores que as demais. Estas espécies de gramas exigem solo fértil (Richter, 1983). Com isto pode-se afirmar que seu desenvolvimento foi favorecido com estes substratos porque, o Plantmax por ser um produto comercial possui na sua formulação uma cierta quantidade de nutrientes. Também o substrato $E$ que consta de vermiculita e esterco bovino curtido muito utilizado como adubo por liberar nutrientes, proporcionou os elementos necessários para o bom crescimento, além de produzir mudas precoces, porque com 30 dias já estavam prontas para ser transplantadas no campo.

Na espécie Esmeralda não houve diferença significativa entre as médias dos substratos; sendo portanto indiferente o uso de qualquer um deles.

O registro fotográfico dos resultados acima relatados podem ser observados nas figuras 4 e 5 . 
Uma melhor visualização dos resultados para a variável MSPA, em função das espécies de gramas e substratos, nas duas épocas, é dada pela Figura 7.

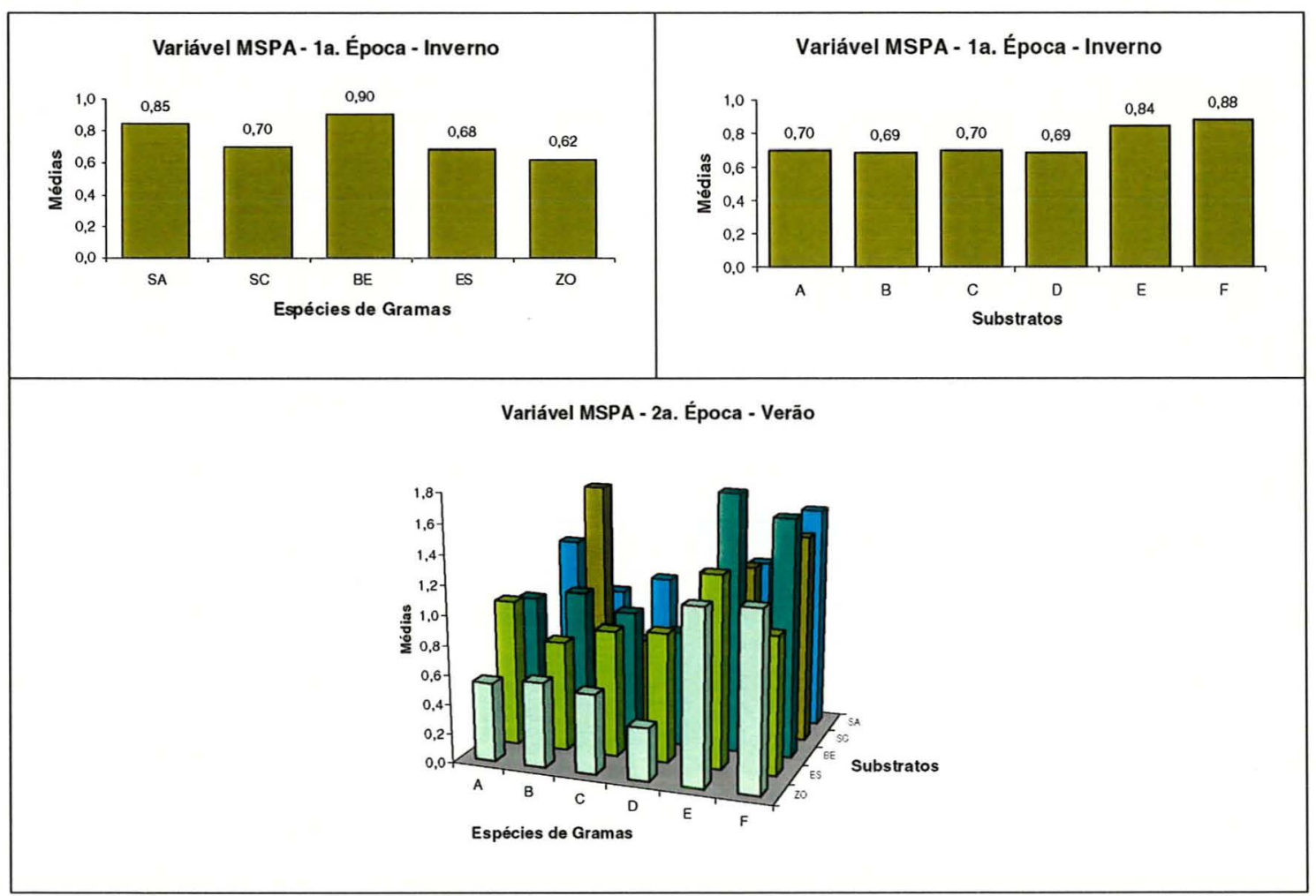

Figura 7 - Médias da variável MSPA para as duas épocas em função das espécie de gramas e das misturas de substratos. 


\section{CONCLUSÕES}

De acordo com os resultados e nas condições em que foi desenvolvido o experimento, pode-se concluir que:

- A espécie Santo Agostinho, independentemente do substrato utilizado, obteve as melhores médias para todos os parâmetros avaliados nas duas épocas de cultivo.

- A espécie Zoysia, independentemente do substrato utilizado, teve um lento crescimento, que foi mais acentuado durante os meses de inverno.

- O substrato A, composto de casca de arroz carbonizada + vermiculita (1:2), destacou-se em relação aos demais como um excelente substrato, dando os melhores resultados nos parâmetros massa seca de raiz e parte aérea para as espécies Santo Agostinho, Bermuda e Esmeralda.

- O substrato B composto de (casca de pinus $75 \%+$ casca de eucaliptus $25 \%$ ) + turfa + casca de arroz (1:1:1) carbonizada apresentou as melhores médias para espécie São Carlos.

- O substratos, C, compostos de casca de pinus + turfa + vermicullita (2:1:1), e D, vermicullita + casca de eucaliptos (2:1) apresentaram os piores resultados com todas as espécies de gramas. 
- O substrato $E$ composto de matéria orgânica + vermicullita (1:2) e F que representa o Plantmax, apresentaram os melhores resultados para as espécies Zoysia e Bermudas. 


\section{REFERÊNCIAS BIBLIOGRÁFICAS}

ANDRIOLO, J.L. O cultivo de plantas com fertirrigação. Santa Maria: UFSM, Centro de Ciências Rurais, 1996, 46p.

ANDRIOLO, J.L. Fisiologia das culturas protegidas. Santa Maria-RS: Ed. da UFSM, 1999, 142p.

AGUIAR, I.B.; VALERI, S.V.; BANZATO, D.A. et al. Seleção de componentes de substrato para produção de mudas de eucalipto e tubetes. Instituto de Pesquisas de Estudos Florestais. n. 41/42, p. 36-43, 1989.

ARRUDA, S.T.; OLIVETTE, M.P.A.; CASTRO, C.E.F. Diagnóstico da floricultura do Estado de São Paulo. Revista Brasileira de Horticultura Ornamental, v.2, n.2, p.1-18, 1996.

BALLESTER-OLMOS, J.F. Substratos para el cultivo de plantas ornamentales. Hojas Divulgadoras, n. 11, p.1-44, 1992.

BACKES, M.A.; KAMPF, A.N.; BORDAS, J.M. Substratos para produção de plantas viveiros. Trigo e Soja, Porto Alegre, n.102, p.5-8, 1989.

BARRET, R.L. The use of planter flats for raising forest nursery stock. South African Forestry Journal, n.117, p.65-67, 1981.

BERINGER, $H$. O potássio na produção das culturas. In: SIMPOSIO SOBRE POTÁSSIO NA AGRICULTURA BRASILEIRA, Londrina, 1982. Resumos. Instituto da Potassa e Fosfato/ Instituto Internacional de Potassa/ IAPAR, 1982. p. 163-175. 
BUNT, A.C. Some physical properties of pot plants composts and their effect on plant growth. II Air capacite of substrates. Plants and Soil. v.15, n.1, p.1424, 1961.

BUNT, A.C. Factors contributing to the delay in the flowering of pot chrysanthemus grown in peat-sand substrates. Acta Horticulturae. v.31, p.163-174, 1973.

CADAHIA, C. Fertirigación: cultivos hortícolas y ornamentales. Madrid: MundiPrensa, 1998, 475p.

CATI., Boletin Técnico. Cultivo em Ambiente Protegido. n. 232, p.24-27, 1997.

DE BOOT, M.; VERDONCK, O. The physical properties of the substrates in horticulture. Acta Horticulturae. v.26, p.37-40, 1972.

DEMATTE, J.B.I; DEMATTE, M.E.S.P. Estudos hídricos com substratos vegetais para cultivo de orquídeas epifitas. Pesquisa Agropecuária Brasileira, v. 31, n. 11, p. 803-813, 1996.

DUTRA, L.F.; KERSTEN, E. Efeito do substrato e da época de coleta dos ramos no enraizamento de estacas de ameixeira (Prunus salicina Lindl.). Ciência Rural. v. 26, n. 3, p.361-366, 1996.

FACHINELLO, J.C.; HOFFMANN, A.; MENEZES, A.L. et al. Efeito do ácido indolbutírico e PVP no enraizamento de estacas de araçazeiro (Psidium cotteyanum Sabine) em diferentes substratos. Revista Brasileira de Fisiologia Vegetal, São Carlos, v. 5, n. 1, 1994. Resumo

GALHANGER, P.A. Peat in protected cropping. In: ROBINSON, D.W.; LAMB, J.G.D. Peat in horticultural. London: Academic Press, 1975, v. 3, p. 133145.

GOMES, J.M.; PEREIRA, A.R.; REZENDE, G.C.de; MACIEL, L.A.F. Uso de diferentes substratos na produção de mudas de Eucalyptus grandis em tubetes em bandejas de isopor. Revista Árvore, v. 9, n. 1, p. 58-86, 1985.

GONÇALVES, A. L.. Substratos artificiais para a produção de mudas de calanchoe, Kalanchoe blossfeldiana c.v. Singapur, Crassulaceae. 
Piracicaba, 1992. 112p. Tese (Doutorado). Escola Superior de Agricultura "Luiz de Queiroz", Universidade de São Paulo.

GONÇALVES, J.L.M. Uso de resíduo industrial como substrato para produção de mudas em tubetes na Ripasa Florestal S.A.. In: SIMÕES,J.K. Problemática da produção de mudas em essências florestais. Série Técnica IPEF, v. 4, n. 13, p. 18-20, 1987.

GRACIANO, T; DEMATTE, J.; VOLPE, C.; PERECIN, D. Interação entre substratos e fertirrigação na germinação e na produção de mudas de Tagetes patula L. (Compositae). Revista Brasileira de Horticultura Ornamental, v. 1, n.2, p. 78-85, 1995.

GROLLI, P.R. Composto de lixo domiciliar urbano como condicionador de substratos para plantas arbóreas. Porto Alegre, 1991. 125 p. Dissertação. Universidade Federal de Rio Grande do Sul.

HARTMANN, H.T.; KESTER, D.E. Propagação de plantas: Principios y Prácticas. México: Compañia Editorial Continental, 1994, 760p.

HODGSON, T.J. Growing media for container nurseries : An interin statement. South African Forestry juornal. n.117, p.34-36, 1981.

HOFFMANN, A.; NACHTIGAL, J.C.; ROSSAL, P.A.L., et al. Influência do substrato sobre o enraizamento de estacas semilenhosas de figueira e araçazeiro. Revista Brasileira de Fruticultura, v. 16, n.1, p. 302-307, 1994.

ITOGRASS. Gramados: Edição especial da Itograss. São Paulo: Europa, 1997, $67 p$.

JESUS, R.M.; MENANDRO, M.S.; COUTO, H.T.Z. Efeito do tamanho do recipiente, tipo de substrato e sombreamento na produção de mudas de louro Cordia trichotoma Vell. e Gonçalo-Alves Astronium fraxinifolium Schott. Instituto de Pesquisas e Estudos Florestais, n. 37, p.13-19, 1987. JUNG, M.; KAMPF, A.N.; BACKES, M.A. Determinação da necessidade de calagem em turfas do Município de Viamão, RS. In: CONGRESSO BRASILEIRO DE FLORICULTURA E PLANTAS ORNAMENTAIS, 6. 
Campinas, 1987. Resumos. Campinas: Sociedade Brasileira de Floricultura e Plantas Ornamentais, 1987. p. 192-205.

KAMPF, A. N. Substratos para floricultura. In: CASTRO, C.E.F.; ANGELIS, B.L.D. DE; MOURA, L.P.P DE. coord. Manual de floricultura. Maringá: 2.ed., cap. 7, p. 201-211, 1992.

KAMPF, A. N. Substratos hortícolas : turfa e casca de arroz. Lavoura Arrozeira. v.46, n. 409, p. 12-13, 1.993.

KAMPF, A. N. Produção comercial de plantas ornamentais. Guaíba-RS: Agropecuária Ltda., 2000, 254p.

KANASHIRO, S. Efeitos de diferentes substratos na produção da espécie Aechmea fasciata (Lindley) Baker em vasos. Piracicaba, 1999. 79p. Dissertação (M.S.). Escola Superior de Agricultura "Luiz de Queiroz", Universidade de São Paulo.

KANAMORI, T.; YASUDA, T. The behavior of nitrogen applied to the uplant soil together whit several organic matters. The transformation of nitrogen in fertilizer and fresh organic matters during the decomposition of rice straw and peat moss applied to the soil (Sumary). Bulletim of the vegetable and ornamental crops research station, serie A, v. 3, p. 94-95, 1977.

KASMOV, R.M. Utilization the soil mixed with porous materials for growing capsicum. Horticultural Abstracts, v. 48, p.136-1458, 1974.

KEEVER, G.J.; COBB, G.S. Effects of container volume an fertiluty rate on growth of two woody ornamentals. Hort Science. v.22, n.5, p.891-893, 1987.

KLEPPER, B. Root-Shoot relationships. IN: WAISEL,Y.; ESHEL, A. ; KAFKAFI, V. Plants Root the hidden half. New York, Marcel Dekker, 1991. p.265-286. LANGHANS, R.W. Greenhouse management. Halcyon Press of Ithaca USA, 1980 , p. 2-29.

LEMAIRE, F.; DARTIGUES, A.; RIVIERE, L.M.; Physical and chemical characteristies of lignocellulose material. Acta Horticulturae, n. 238, p.9-22, 1988. 
LORENZI, H., SOUZA, H.M. Plantas ornamentais no Brasil. Edit. Plantarum Ltda. São Paulo-Brasil. 720p. 1995.

LORENZI, H., SOUZA, H.M. Plantas ornamentais no Brasil. Nova Odesa SP: Instituto Plantarum Ltda., 1999, 1087p.

MASTALERZ, J.W. The greenhouse enrichment. John Wiley and Sons. USA, p. $1-8$ e $68-78,1977$.

MATTOS, P.P. de; DONADIO, L.C.; BANZATO, D.A. Efeito do uso de diferentes substratos sobre o desenvolvimento de três porta-enxertos de citros em recipientes. In: CONGRESSO BRASILEIRO DE FRUTICULTURA, 9. Campinas: Sociedade Brasileira de Fruticultura, p. $351-354,1988$.

MELO, A.C.G. Efeito de recipiente e substrato no comportamento silvicultural de plantas de Eucalyptus grandis Hill ex Maiden e do Eucalyptus urophylla St. Brake. Piracicaba, 1989, 40p. Dissertação (M.S.) - Escola Superior de Agricultura "Luiz de Queiroz", Universidade de São Paulo.

MACDONALD, B. Practical woody plant propagation for nursery growers. Portland: Timber Press, 663p, 1993.

MINAMI, K. Vermiculita e seu emprego na horticultura. Piracicaba: ESALQ, Departamento de Produção Vegetal, 1980, 12p.

MINAMI, K. Vermiculita. IN: VII Semana de Ciencia e Tecnologia Agropecuaria de Jaboticabal, p.5, 1982.

MINAMI, K. Produção de Mudas de Alta Qualidade em Horticultura. São Paulo: T. A. Editor, 1995. 128p.

MOURÃO FILHO, F.A.A.; DIAS, C.T.S.; SALIBE, A.A. Efeito da composição do substrato na formação de mudas de laranjeira "Pera". Scientia Agricola, v. 55, n. 1, p. 35-42, 1998.

NAKAMURA, S.; WABE, S. Studies on standard composts for potted flowering plants. The physical standardization of composts basec on the sawdust and chaff content, and effects on plant growth. Horticultural Abstracts, v. 44, p. $583,1974$. 
ORLANDER, G., DUE, K. Location of hidraulic resistante in the soil plant pathway in seedling of Pinus silvestris L. grown in peat. Canadian Journal of Forest Research, v.16, n.11, p. 115-123, 1986.

PLANTAS E FLORES: Gramados. São Paulo: Abril Cutural, 1971, 408p.

RICHARDS, S.J., WERNECKE, J.E., MARSH, A.J., ALJIBURY, F.K. Physical properties of soil mixes. Soil Science. n. 98, p.129-132, 1964.

RICHER-LECLERC,C. Sylvagrest : a new growing medium for ornamental plants. Canada Agriculture, v.30, n.2, p.32, 1984.

RICHTER, N.T. Gramado, uma extensão verde. Lavoura Arrozeira. v.46, n. 409 , p. $12-13,1.993$

RICHTER, N.T. Gramado, uma extensão verde. Casa da Agricultura. n. 6, p. 19-22, 1983.

SALVADOR, E.D. Efeito de diferentes substratos no crescimento e desenvolvimento de samambaia matogrossense Polypodium aureum. 1.995 Lavras, 1995. 64 p. Dissertação. Universidade Federal de Lavras.

SHEPS, I. \& SOUZA, E. O lixo volta a ser árvore. Globo Rural, v. 3, n. 31, p. 48-55, 1988.

SILVA, W. Produção de mudas de hortalizas em bandejas. IN:CONGRESSO BRASILEIRO DE OLERICULTURA, 31., Belo Horizonte, 1.991. Resumos. Belo Horizonte, 1991. p.162-165.

SOUZA, E. ; SOUZA, P. de. Utilização da vermicullita no plantio de essencias florestais. 1983. (Apostila de aula de graduação)

SOUZA, F. de. Casca de arroz carbonizada: um substrato para propagação de plantas. Lavoura Arrozeira, v. 46, p.11, 1993.

SOUZA, M.M.; LOPEZ, L.C.; FONTES, L.E. Avaliação de Substratos para o cultivo do Crisantemo (Chrysanthemun morifolium Ramat., Compositae) White Polaris em vasos. Revista Brasileira de Horticultura Ornamental. v.1, n.2, p. 71-74, 1995. 
SOUZA, P.; COUTINHO, C.J. Produção de mudas de Eucaliptus saligna em bandejas de isopor. IN: CONGRESO FLORESTAL BRASILEIRO, 4. Belo Horizonte. 1982. Resumos. Belo Horizonte, 1982. p.67.

SOUZA, R.J.; FERREIRA, A. Produção de mudas de hortaliças em bandejas: economia de sementes e defensivos. A Laoura, n. 623, p.19-21, 1997.

SPURR, S.N., BARNES, B.N. Forest ecology. New York. The Ronald Press. 1973. 571p.

STRINGHETA, A.C.O. Avaliação de variedades de crisântemo em vasos em substratos contendo compostos de lixo urbano. Viçosa, 1995, 72p. Dissertação (M.S.) - Universidade Federal de Viçosa.

TAKEYOSHI, N.L.; ANRAKU, R.N.; MINAMI, K. et al. Efeitos de diversos substratos no enraizamento de estacas de Crysanthemum morifolium cv. Polaris. In: CONGRESSO BRASILEIRO DE FLORICULTURA E PLANTAS ORNAMENTAIS, 9., Rio de Janeiro, 1983. Resumos. Rio de Janeiro, 1983 p. 137-143.

TOMBOLATO, A.F.C.; CASTRO, C.E.F.; MATHES, L.A.F. et al. Tipos de substratos para formação de mudas de violeta africana (Saintpaulia ionantha $\mathrm{H}$. Wendl). VI CONGRESSO BRASILEIRO DE FLORICULTURA DE PLANTAS ORNAMENTAIS. Campinas, 1987. Resumos. Campinas, $1987,113 p$.

TULLIO JR., A.A.; NOGUEIRA, R.R.; MINAMI, K. Uso de diferentes substratos na germinação e formação de mudas de pimentão (Capsicum annuum L.). O solo, v.78, p.15-18, 1986.

VERDONCK, O. Utilization of pine bark compost in horticulture. Compost Science, v. 21, n. 1, p. 22-23, 1980. 